\title{
Three-dimensional ordered porous electrode materials for electrochemical energy storage
}

\author{
Zaichun Liu' ${ }^{1,2}$, Xinhai Yuan², Shuaishuai Zhang ${ }^{2}$, Jing Wang ${ }^{2}$, Qinghong Huang ${ }^{2}$, Nengfei Yu², Yusong Zhu ${ }^{2}$, Lijun Fu ${ }^{1,2}$, \\ Faxing Wang ${ }^{3}$, Yuhui Chen ${ }^{1,2}$ and Yuping Wu (id,
}

\begin{abstract}
The past decade has witnessed substantial advances in the synthesis of various electrode materials with threedimensional (3D) ordered macroporous or mesoporous structures (the so-called "inverse opals") for applications in electrochemical energy storage devices. This review summarizes recent advancements in 3D ordered porous (3DOP) electrode materials and their unusual electrochemical properties endowed by their intrinsic and geometric structures. The 3DOP electrode materials discussed here mainly include carbon materials, transition metal oxides (such as $\mathrm{TiO}_{2}$, $\mathrm{SnO}_{2}, \mathrm{Co}_{3} \mathrm{O}_{4}, \mathrm{NiO}, \mathrm{Fe}_{2} \mathrm{O}_{3}, \mathrm{~V}_{2} \mathrm{O}_{5}, \mathrm{Cu}_{2} \mathrm{O}, \mathrm{MnO}_{2}$, and $\mathrm{GeO}_{2}$ ), transition metal dichalcogenides (such as $\mathrm{MoS}_{2}$ and $\mathrm{WS}_{2}$ ), elementary substances (such as $\mathrm{Si}, \mathrm{Ge}$, and $\mathrm{Au}$ ), intercalation compounds (such as $\mathrm{Li}_{4} \mathrm{Ti}_{5} \mathrm{O}_{12}, \mathrm{LiCoO}_{2}, \mathrm{LiMn}_{2} \mathrm{O}_{4}, \mathrm{LiFePO}_{4}$ ), and conductive polymers (polypyrrole and polyaniline). Representative applications of these materials in Li ion batteries, aqueous rechargeable lithium batteries, Li-S batteries, $\mathrm{Li}_{-} \mathrm{O}_{2}$ batteries, and supercapacitors are presented. Particular focus is placed on how ordered porous structures influence the electrochemical performance of electrode materials. Additionally, we discuss research opportunities as well as the current challenges to facilitate further contributions to this emerging research frontier.
\end{abstract}

\section{Introduction}

The continued exploration of green and sustainable energy storage devices is critical for addressing the worldwide problems of limited availability of fossil fuels and environmental pollution. Among various energy storage technologies, electrochemical energy storage devices are the most promising and common devices. Currently, research on electrochemical energy storage is mainly focused on supercapacitors and rechargeable batteries $^{1-5}$. Supercapacitors have high power densities and long cycling lives explained by surface charge storage mechanisms, while rechargeable batteries deliver high

Correspondence: Jing Wang (wjx2015@njtech.edu.cn) or Faxing Wang (faxing. wang@tu-dresden.de) or Yuping Wu (wuyp@fudan.edu.cn)

'State Key Laboratory of Materials-oriented Chemical Engineering, Nanjing Tech University, 211816 Nanjing, China

${ }^{2}$ Institute for Advanced Materials, School of Energy Science and Engineering, Nanjing Tech University, 211816 Nanjing, Jiangsu Province, China

Full list of author information is available at the end of the article. energy densities due to the Faradaic charge storage mechanism ${ }^{2,6-8}$. In the past three decades, $\mathrm{Li}$ ion batteries have served as the primary power supply for various portable electronic devices. However, intercalation-type electrode materials for $\mathrm{Li}$ ion batteries have reached their performance limit. Thus significant attention has been focused on high-capacity conversion reaction-type cathodes, such as sulfur (Li-S batteries) and oxygen $\left(\mathrm{Li}-\mathrm{O}_{2}\right.$ batteries $)^{9-12}$. In addition, low-cost and safe aqueous rechargeable batteries are promising candidates for largescale electrical energy storage systems. For any electrochemical energy storage device, electrode materials as the major constituent are key factors in achieving high energy and power densities. Over the past two decades, to develop high-performance electrode materials, researchers have designed and integrated one-dimensional (1D) (nanowires, nanoribbons, nanotubes), two-dimensional (2D) (nanosheets, nanoplates, nanomembranes), and

\section{(c) The Author(s) 2019}

(c) Open Access This article is licensed under a Creative Commons Attribution 4.0 International License, which permits use, sharing, adaptation, distribution and reproduction cc) in any medium or format, as long as you give appropriate credit to the original author(s) and the source, provide a link to the Creative Commons license, and indicate if changes were made. The images or other third party material in this article are included in the article's Creative Commons license, unless indicated otherwise in a credit line to the material. If material is not included in the article's Creative Commons license and your intended use is not permitted by statutory regulation or exceeds the permitted use, you will need to obtain permission directly from the copyright holder. To view a copy of this license, visit http://creativecommons.org/licenses/by/4.0/. 
three-dimensional (3D) architectures into electrode materials. Although 1D and 2D electrode materials with high stabilities and efficient charge-transport paths have been demonstrated ${ }^{13,14}$, they still suffer from severe aggregation, which prevents the easy diffusion of electrolytes and fast kinetics of electrochemical reactions. To this end, engineering 3D structural configurations with interconnected porous channels is one of the most effective strategies to resolve the abovementioned problems. Moreover, in the practical fabrication of electrodes for use in commercial batteries and supercapacitors, the electrode materials will be squeezed, thus forming disordered 3D structures. These 3D structures in commercial bulk electrodes will be a benefit to electrolyte transportation and ion diffusion. For 3D materials, squeeze processing during industrial production will result in dual-3D structures in electrodes and favor superior electrolyte transportation and ion diffusion.

Among various 3D architectures, the 3D ordered porous (3DOP) structure is highly desirable for constructing high-performance electrode materials in electrochemical energy storage systems ${ }^{1,15-23}$. Generally, 3DOP materials are prepared through colloidal crystal templating strategies ${ }^{20-23}$. First, uniform monodispersed microspheres, such as polystyrene (PS), silica or poly(methyl methacrylate) spheres, are assembled into 3D ordered arrays via dense packing. Second, various precursors can infiltrate into the 3D ordered scaffold. Finally, solidification of the precursor and removal of the colloidal spheres are performed to obtain periodic 3D framework structures. To obtain the 3DOP nanocomposites, there are two typical methods. In the first method, in the second step, more desired active species can be directly introduced into the 3DOP templates by using the corresponding multicomponent solution as precursors. In the other method, the 3DOP material is utilized as a host structure for the further growth of active electrode materials by various growth mechanisms. Currently, it is well accepted that the spatial orientation/arrangement of 3DOP structures can not only shorten the diffusion path of ions within the thin walls of electrode materials but also improve the robust structural integrity of electrode materials during longtime cycles. Specifically, 3DOP electrode materials have better rate capabilities than nanocrystalline materials (in which the nanoparticles are loosely aggregated together) because the bicontinuous ordered 3D frameworks can ensure much higher metal ion flux across the electrode and serve as a pathway for efficient electron transport within the whole 3D scaffold. Furthermore, the free space within porous $3 \mathrm{D}$ electrodes can act as a buffer against volume variation of the entire electrode, thus reducing mechanical strain during the repeated charge-discharge processes.
To date, many reviews have summarized 3D porous materials and their applications in energy storage and conversion fields ${ }^{1,15,16,24-26}$. For example, several early reviews from Rolison's group focused on the design and fabrication of multifunctional 3D nanoarchitectures for microbatteries, supercapacitors, fuel cells, and photovoltaic cells ${ }^{27-29}$. Recent progress in porous mixed metal oxides, including their synthesis, formation mechanism, and application in $\mathrm{Li}$ ion batteries, was discussed in $2015^{30}$. In 2017, an overview of representative work on holey 2D nanomaterials-from general methodologies to their promising applications in various electrochemical energy storage devices-was provided ${ }^{15}$. However, with the rapid development of new materials and fabrication technologies, a systematic review regarding the progress of 3DOP electrode material for electrochemical energy storage systems, is still lacking. In this review, we summarize the recent progress of 3DOP electrode materials and their unusual electrochemical properties resulting from their intrinsic and geometric structures. Figure 1 summarizes representative 3DOP electrode materials and their applications in various electrochemical energy storage devices (metal ion batteries, aqueous batteries, Li-S batteries, $\mathrm{Li}^{-} \mathrm{O}_{2}$ batteries, and supercapacitors). Emphasis is placed on the special 3DOP configuration and its corresponding effects on the enhancement of electrochemical properties. Research opportunities, as well as challenges, are also discussed to facilitate further research and development in this promising field.

\section{DOP electrode materials for use in Li ion batteries Anode materials}

Titanium dioxide $\left(\mathrm{TiO}_{2}\right)$ has been well studied as an anode for Li ion storage because it is chemically stable, abundant, inexpensive, and environmentally benign.

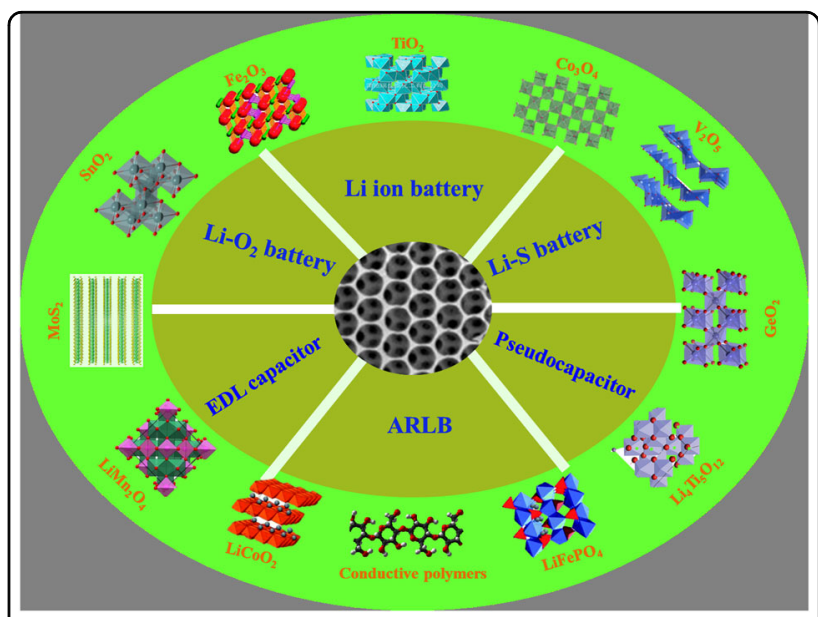

Fig. 1 An overview of three-dimensional ordered porous electrode materials for use in various electrochemical energy storage devices 
Three types of $\mathrm{TiO}_{2}$ have been well investigated, namely, $\mathrm{TiO}_{2}(\mathrm{~B})$, anatase, and rutile. Among them, the rutile phase of $\mathrm{TiO}_{2}$ is the most common natural form since it is the most thermodynamically stable phase under normal conditions. $\mathrm{Li}$ ion intercalation and deintercalation in $\mathrm{TiO}_{2}$ involve much higher operating potentials $(\sim 1.5 \mathrm{~V}$ vs. $\left.\mathrm{Li}^{+} / \mathrm{Li}\right)$ than those in graphite $\left(\sim 0.2 \mathrm{~V} \text { vs. } \mathrm{Li}^{+} / \mathrm{Li}\right)^{31-33}$. Although this operating potential cannot completely prevent the formation of a solid-electrolyte interphase (SEI) film, it eliminates the problem of lithium plating and dendrite formation. Early studies on $3 \mathrm{DOP} \mathrm{TiO}_{2}$ electrodes for $\mathrm{Li}$ ion batteries date back to 2007, when Professor Wu's group reported that as-synthesized $\mathrm{TiO}_{2}$ with a 3DOP architecture exhibited a higher specific capacity and better cycling behavior than conventional $\mathrm{TiO}_{2}{ }^{34}$. Indeed, decreasing the particle size of $\mathrm{TiO}_{2}$ to nanoscale dimensions can allow higher reversible capacity and faster charge-discharge rates due to the shortened pathlength for diffusion of Li ions. Specifically, the dense packing of nanoparticles due to aggregation reduces the overall surface area contact with the electrolyte (Fig. 2a). Thus deeper layers of active $\mathrm{TiO}_{2}$ nanoparticles may not be completely accessible for lithiation. For the $3 \mathrm{DOP} \mathrm{TiO}_{2}$ electrode, the ordered porosity of the electrode ensures an even distribution of contact between the electrode and the electrolyte, as shown in Fig. $2 b$, which thus improves the mass transfer of electrolyte ions to the electrode surface and promotes complete lithiation ${ }^{35}$. Moreover, thin pore walls in 3DOP materials enable short $\mathrm{Li}$ ion diffusion paths. Therefore, the 3DOP $\mathrm{TiO}_{2}$ electrode shows a higher specific capacity and better rate capability than its nanoparticle counterpart.

Interestingly, another 3DOP rutile $\mathrm{TiO}_{2}$ electrode presents an initial discharge capacity of up to $608 \mathrm{mAh} \mathrm{g}^{-1}$, which is much higher than the theoretical capacity for $\mathrm{TiO}_{2}\left(168 \mathrm{mAhg}^{-1}\right.$ for $\mathrm{Li}_{0.5} \mathrm{TiO}_{2}$ or $336 \mathrm{mAhg}^{-1}$ for $\left.\mathrm{LiTiO}_{2}\right)^{36}$. Such high capacity mainly results from some formed defects that serve as additional chargecompensation sites. Moreover, an impressive cycling stability of up to 5000 cycles is achieved in this 3DOP rutile $\mathrm{TiO}_{2}$ electrode in the absence of any binders or conductive additives. During the repeated insertion and removal of $\mathrm{Li}$ ions, the nanowalls in these 3DOP rutile $\mathrm{TiO}_{2}$ electrodes are swollen but still maintain the 3DOP structure very well even after 1000 and 5000 cycles (Fig. 2c), demonstrating an extremely high level of structural integrity ${ }^{36}$. Thus another advantage of the 3DOP electrode is that its periodic OP structure allows the interconnected walls to expand into the empty pores, preventing the walls from becoming pulverized.

Through a synergic dual template of the colloidal crystal and surfactant, the 3DOP $\mathrm{TiO}_{2} / \mathrm{C}$ nanocomposite was prepared with a phenol-formaldehyde sol as an amorphous carbon source ${ }^{37}$. Detailed synthetic conditions, including the choice of chelating agents and temperatures, were investigated and optimized. Upon pyrolysis at $800{ }^{\circ} \mathrm{C}$ using 2,4-pentadiene as a chelating agent, the obtained 3DOP $\mathrm{TiO}_{2} / \mathrm{C}$ composites display the highest specific capacity. The $\mathrm{TiO}_{2}$ content in the pyrolyzed $\mathrm{TiO}_{2} / \mathrm{C}$ composite is approximately $70 \%{ }^{37}$. Upon decreasing the $\mathrm{TiO}_{2}$ content and increasing the amorphous carbon content, a high capacity of $549 \mathrm{mAh} \mathrm{g}^{-1}$ is achieved in another 3DOP $\mathrm{TiO}_{2} / \mathrm{C}$ nanocomposite with $55 \mathrm{wt} \%$ $\mathrm{TiO}_{2}{ }^{38}$. The ultrahigh specific capacity originates from the contribution of $\mathrm{Li}$ ion intercalation to the nongraphic carbon. Although 3DOP $\mathrm{TiO}_{2}$ electrode materials deliver high capacity, even more than the theoretical value, the main contribution to capacity is within the potential range of $1.5-3.0 \mathrm{~V}$ (vs. $\mathrm{Li}^{+} / \mathrm{Li}$ ). Such high potentials allow the $\mathrm{TiO}_{2}$-based anode materials to appropriately couple only with cathode materials with high potentials.

Transition cobalt oxides are widely considered attractive anode materials for $\mathrm{Li}$ ion batteries because of their high theoretical capacities $\left(890 \mathrm{mAh} \mathrm{g}^{-1}\right.$ for $\mathrm{Co}_{3} \mathrm{O}_{4}$ and $716 \mathrm{mAh} \mathrm{g}^{-1}$ for $\left.\mathrm{CoO}\right)^{39-41}$. Currently, the practical application of cobalt oxides in $\mathrm{Li}$ ion batteries is seriously hindered by the poor capacity retention over long-time cycling due to relatively large volume changes. To alleviate this problem, 3DOP carbon inverse opals have been utilized to entrap $\mathrm{CoO}$ nanoparticles ${ }^{42}$. The 3DOP $\mathrm{CoO} / \mathrm{C}$ electrode displays a high capacity of $674 \mathrm{mAh} \mathrm{g}^{-1}$ even after 1000 cycles, accounting for $94 \%$ of the theoretical capacity. The 3DOP carbon structure serves as not only the interpenetrating continuous conductive network but also a dimensional constraint to active nanoparticles.

In addition to the 3DOP carbon, the 3DOP Ni scaffold has been uniformly utilized for the deposition of $\mathrm{Co}_{3} \mathrm{O}_{4}$ nanosheets ${ }^{43,44}$. The thickness of the $\mathrm{Co}_{3} \mathrm{O}_{4}$ nanosheets can be easily controlled by adjusting the hydrothermal growth conditions. The initial discharge and charge capacities of the 3DOP $\mathrm{Co}_{3} \mathrm{O}_{4} / \mathrm{Ni} / \mathrm{Au}$ electrode are 1478 and $1224 \mathrm{mAh} \mathrm{g}^{-1}$, respectively, which are much higher than the theoretical capacity of $\mathrm{Co}_{3} \mathrm{O}_{4}{ }^{44}$. The additional capacity results from the contribution of $\mathrm{Li}$ ion alloying reactions with $\mathrm{Au}^{45}$. The reversible redox reaction between $\mathrm{Au}$ and $\mathrm{Li}$ ions presents several sharp redox peaks below $0.5 \mathrm{~V}$ (vs. $\left.\mathrm{Li}^{+} / \mathrm{Li}\right)$. No redox peaks from the bare 3DOP $\mathrm{Ni}$ electrode were detected, indicating the stability of the 3D Ni as a scaffold.

Among the various transition metal oxides, iron oxides are another extensively studied anode because they offer several benefits, including high theoretical capacities (926 $\mathrm{mAh} \mathrm{g}^{-1}$ for $\mathrm{Fe}_{3} \mathrm{O}_{4}$ and $1007 \mathrm{mAh} \mathrm{g}^{-1}$ for $\mathrm{Fe}_{2} \mathrm{O}_{3}$ ), high tap density $\left(5.1-5.3 \mathrm{~g} \mathrm{~cm}^{-3}\right)$, abundant resources, and environmentally friendly characteristics. A recent study demonstrates that 3DOP $\alpha-\mathrm{Fe}_{2} \mathrm{O}_{3}$ with a pore size of $\sim 250 \mathrm{~nm}$ exhibits initial discharge and charge capacities of 1883 and $1139 \mathrm{mAh} \mathrm{g}^{-1}$, respectively ${ }^{46}$, which are 


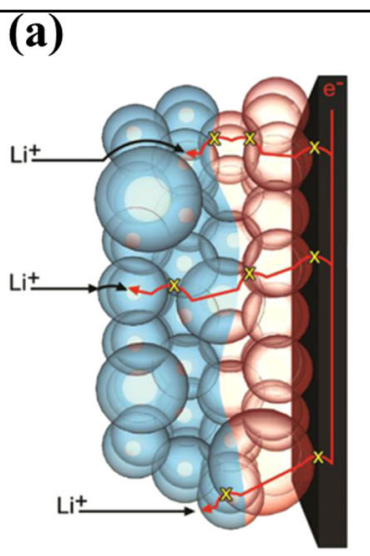

(b)

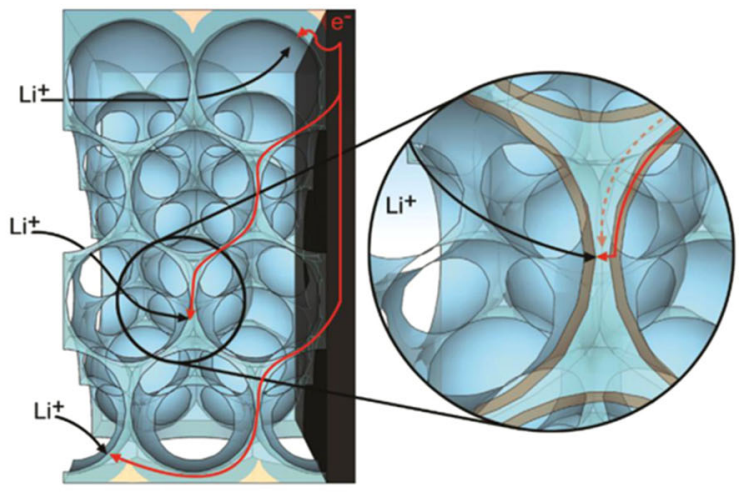

(c)
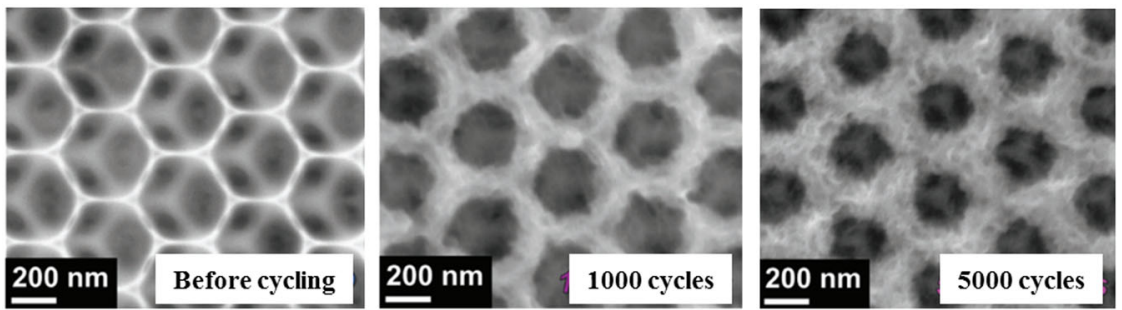

Fig. 2 The 3DOP structure in $\mathrm{TiO}_{2}$ anode for fast ion and electron transport as well as the accommodation of volume change during cycling. Schematic illustration of the lithiation pathways for $\mathbf{a}$ nanoparticle and $\mathbf{b}$ three-dimensional ordered porous (3DOP) electrodes. The active material ( $\left(\mathrm{TiO}_{2}\right)$ is blue, and potentially inaccessible lithiation sites are highlighted in brown (modified from ref. ${ }^{35}$, copyright permission from Elsevier). c Scanning electron microscopic images of the $3 \mathrm{DOP} \mathrm{TiO}_{2}$ electrode before and after cycles (modified from ref. ${ }^{36}$, copyright permission from Elsevier)

much higher than those of $\alpha-\mathrm{Fe}_{2} \mathrm{O}_{3}$ with a $1 \mathrm{D}$ nanorod structure or a $2 \mathrm{D}$ nanoflake structure ${ }^{47,48}$. In another work, the $\gamma-\mathrm{Fe}_{2} \mathrm{O}_{3}$ nanoparticles were deposited on 3DOP $\mathrm{Ni}$ by pulsed voltage electrodeposition at room temperature ${ }^{49}$. To avoid formation of a thick $\mathrm{Fe}_{2} \mathrm{O}_{3}$ layer at the top of the electrode, the process of pulsed voltage electrodeposition must include a repeated sequence of "on" and "off" voltages. Notably, with an increase in the $\mathrm{Fe}_{2} \mathrm{O}_{3}$ loading, the sizes of pores in the 3DOP Ni would decrease, which may limit the accessibility of the electrolyte to all of the active materials. The optimized loading of $\gamma-\mathrm{Fe}_{2} \mathrm{O}_{3}$ on the 3D DOP Ni current collector is $0.4 \mathrm{mg} \mathrm{cm}^{-2}$. In the cyclic voltammetric (CV) curves, a large reduction peak at approximately $1.5 \mathrm{~V}\left(\mathrm{vs} . \mathrm{Li}^{+} / \mathrm{Li}\right)$ is absent in the first cycle but appears at the beginning of the second cycle (Fig. 3a). This phenomenon may be caused by the "electrochemical grinding effect." Smaller $\mathrm{Fe}_{2} \mathrm{O}_{3}$ particles are produced at the end of the first cycle. Then $\mathrm{Li}^{+}$ions can intercalate into the small $\mathrm{Fe}_{2} \mathrm{O}_{3}$ particles that were produced before complete conversion to $\mathrm{Fe}$ and $\mathrm{Li}_{2} \mathrm{O}$ because of the short diffusion length and high surface area provided by the small domains. Thus this intercalation process leads to a large reduction peak at approximately $1.5 \mathrm{~V}$ (vs. $\mathrm{Li}^{+} / \mathrm{Li}$ ). At room temperature, the voltage hysteresis of the 3DOP $\gamma-\mathrm{Fe}_{2} \mathrm{O}_{3} / \mathrm{Ni}$ electrode is only $0.62 \mathrm{~V}$, as calculated from the separation between the conversion reaction redox peaks (Fig. 3b), which is much smaller than those of other reported $\mathrm{Fe}_{2} \mathrm{O}_{3}$ anodes ${ }^{50}$. When the temperature increases to $45^{\circ} \mathrm{C}$, the voltage hysteresis decreases, with a value of only $0.42 \mathrm{~V}$ (Fig. 3c), which suggests that the voltage hysteresis in the 3DOP $\gamma-\mathrm{Fe}_{2} \mathrm{O}_{3} / \mathrm{Ni}$ electrode could result from a thermal activation process ${ }^{49}$.

The addition of inactive 3DOP current collectors and the loading of low-activity materials on the 3DOP current collectors would lead to low gravimetric and volumetric capacities. In this regard, a scaffold-free 3DOP $\mathrm{Fe}_{3} \mathrm{O}_{4} / \mathrm{C}$ composite without any current collectors or bonding additives has recently been demonstrated ${ }^{51}$. Toward commercial potential applications, the $\mathrm{Fe}_{3} \mathrm{O}_{4} / \mathrm{C}$ anode with a thickness of $100 \mu \mathrm{m}$ is achieved, presenting a specific capacity of $710 \mathrm{mAh} \mathrm{g}^{-1}$ based on the total mass of the whole electrode. The change in the overall dimensions of the electrode is almost unnoticeable because the volume expansion-contraction is buffered by the 3D nanocomposite matrix. In fact, the construction of 3DOP structures and the formation of nanocomposites are unable to completely solve the large intrinsic volume change and pulverization of $\mathrm{Fe}_{2} \mathrm{O}_{3}$ anodes. To avoid intrinsic pulverization of the $\mathrm{Fe}_{2} \mathrm{O}_{3}$ anode, an internally established magnetic field from the additional magnetic component (CoPt) was introduced into the 3DOP $\mathrm{Fe}_{2} \mathrm{O}_{3} /$ $\mathrm{TiO}_{2}$ electrode ${ }^{52}$. After being magnetized by an external 

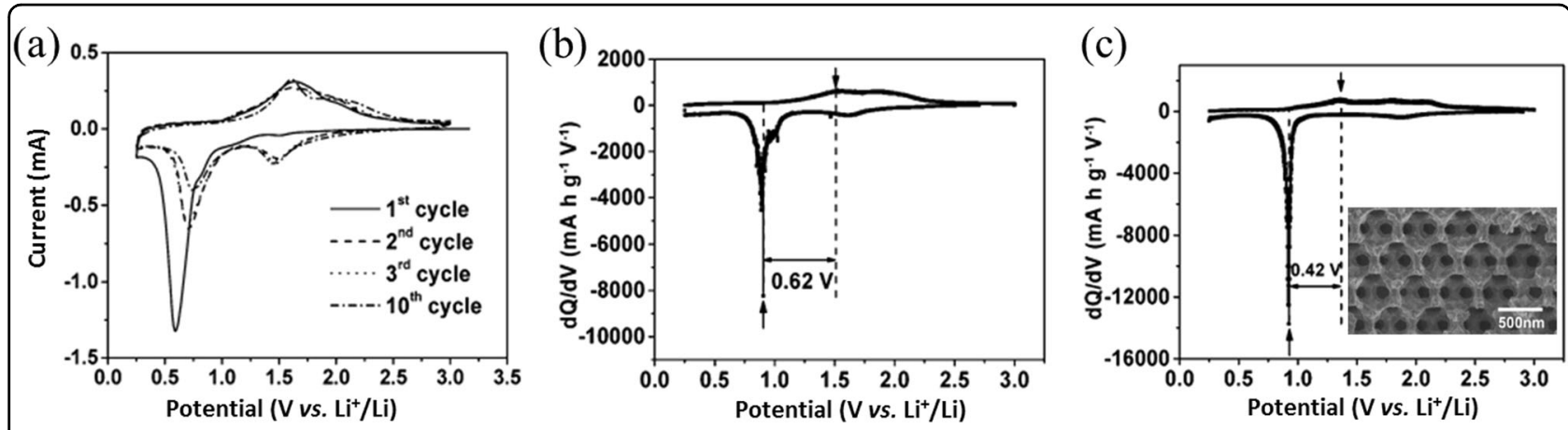

Fig. 3 Electrochemical characterization of three-dimensional ordered porous (3DOP) $\mathrm{Fe}_{2} \mathrm{O}_{3}$ electrodes. a Cyclic voltammetric curves at various cycles. The $\mathrm{dQ} / \mathrm{dV}$ vs. voltage curves of the second cycle at $0.1 \mathrm{~A} \mathrm{~g}^{-1}$ at $\mathbf{b}$ room temperature and $\mathbf{c} 45^{\circ} \mathrm{C}$. The inset is the scanning electron microscopic image of the $3 \mathrm{DOP} \mathrm{Fe}_{2} \mathrm{O}_{3}$ electrode (modified from ref. ${ }^{49}$, copyright permission from the American Chemical Society)

magnetic field as a result of the ferromagnetic nature of $\mathrm{CoPt}$, the constant magnetic field inside of the anode can enable the active material to be tightly bonded to the framework of the electrode even after pulverization occurs.

Tin dioxide $\left(\mathrm{SnO}_{2}\right)$ is also a well-studied anode used in $\mathrm{Li}$ ion batteries, and its charge storage mechanism is based on an irreversible conversion reaction $\left(\mathrm{SnO}_{2} / \mathrm{Sn}+\mathrm{Li}_{2} \mathrm{O}\right)$ combined with a reversible alloying reaction (Sn/ $\left.\mathrm{Li}_{4.4} \mathrm{Sn}\right)^{53-55}$. As early as 2004, the electrochemical study of $\mathrm{SnO}_{2}$ anodes with an inverse opal structure was reported, in which the 3DOP geometry leads to reduced polarization in the alloying region of the $\mathrm{CV}$ curves $^{56}$. Upon initial formation of $\mathrm{Li}_{4.4} \mathrm{Sn}$ from $\mathrm{Sn}$, there should be a theoretical volume expansion of $137 \%$. However, after cycling four times at $0.1 \mathrm{C}$, the wall thickness of the 3DOP $\mathrm{SnO}_{2}$ film is visibly swollen by $650 \%$. This is because the continuous structural degradation of the electrode during cycling results in the separation of additional $\mathrm{Li}_{x} \mathrm{Sn}$ particles, resulting in a continuous expansion of the entire solid structure. Moreover, the expansion of the agglomerated $\mathrm{Li}_{x} \mathrm{Sn}$ alloy region gradually ruptures, resulting in an increase in the fraction of electronically isolated and swollen particles. When cycling at a high rate of $10 \mathrm{C}$, no morphological change was observed in this $3 \mathrm{DOP} \mathrm{SnO}_{2}$ film electrode. Another $3 \mathrm{DOP} \mathrm{SnO}_{2}$ electrode delivers a higher reversible specific capacity $\left(653 \mathrm{mAh} \mathrm{g}^{-1}\right)$ than $\mathrm{SnO}_{2}$ nanoparticles $\left(327 \mathrm{mAh} \mathrm{g}^{-1}\right)^{57}$. The continuous void space of the 3DOP structure can be readily filled with the electrolyte solution, resulting in improved ionic and electronic conductivity of the whole electrode. Thus perhaps one can conclude that 3DOP structures for anodes that combine irreversible conversion reactions and reversible alloying reactions are more favorable for enhancing the rate capabilities instead of the cycling stabilities.

In addition to $\mathrm{SnO}_{2}$, a 3DOP Sn scaffold containing a hollow sphere of Sn coated with carbon was recently demonstrated $^{58}$. The 3DOP Sn/C anode with an electrode thickness of $100 \mu \mathrm{m}$ can retain a volumetric capacity $>650 \mathrm{mAh} \mathrm{cm}^{-3}$ after 100 cycles. The 3DOP structure allows volume expansion and extraction of the active material without changing the overall electrode dimensions during cycling. Thus no obvious volume expansion of the 3DOP $\mathrm{Sn} / \mathrm{C}$ composite occurred after the various lithiation states (the dotted yellow line in Fig. 4) when in contact with the $\mathrm{Li} / \mathrm{Li}_{2} \mathrm{O}$ flake from the in situ transmission electron microscope (TEM) study. For the real-time lithiation of the 3DOP $\mathrm{Sn} / \mathrm{C}$ nanocomposite, a nanoscale battery device was designed and composed of a $\mathrm{Sn} / \mathrm{C}$ nanocomposite as the working electrode and a $\mathrm{Li}$ metal flake covered by a natural thin $\mathrm{Li}_{2} \mathrm{O}$ solid electrolyte layer as a counter electrode. Notably, the abovementioned device that employs a solid $\mathrm{Li}_{2} \mathrm{O}$ on the $\mathrm{Li}$ anode surface as the electrolyte is the most commonly used model of nanobattery for the real-time TEM test. However, such a solid-state set-up cannot accurately represent a standard battery environment using organic liquid electrolytes. In this regard, in situ liquid TEM experiments are highly desired by sealing the liquid electrolytes with two thin membrane windows ${ }^{59}$. However, the thin membrane windows may drastically decrease the spatial resolution of the microscope. Therefore, there is still a long way to achieve in situ TEM electrochemistry of 3DOP electrode materials.

Comparative research on $\mathrm{Si}$ anodes has demonstrated the highest specific capacity among all anode materials, but its largest shortcoming is the large volume expansion (400\%) during alloying/dealloying with $\mathrm{Li}$ ions, greatly restricting their practical application ${ }^{60-63}$. To solve the pulverization problem, several $\mathrm{Si}$ anode-coated 3DOP Ni electrodes (Si/ $\mathrm{Ni}$ ) were fabricated by electrodeposition ${ }^{64-67}$. Based on the electrochemical impedance spectroscopic measurements, the $\mathrm{Li}$ ion diffusion coefficient of the 3DOP $\mathrm{Si} / \mathrm{Ni}$ electrode is larger than that of the Si-nanowire-based electrode because of the different configurations ${ }^{65}$. In 

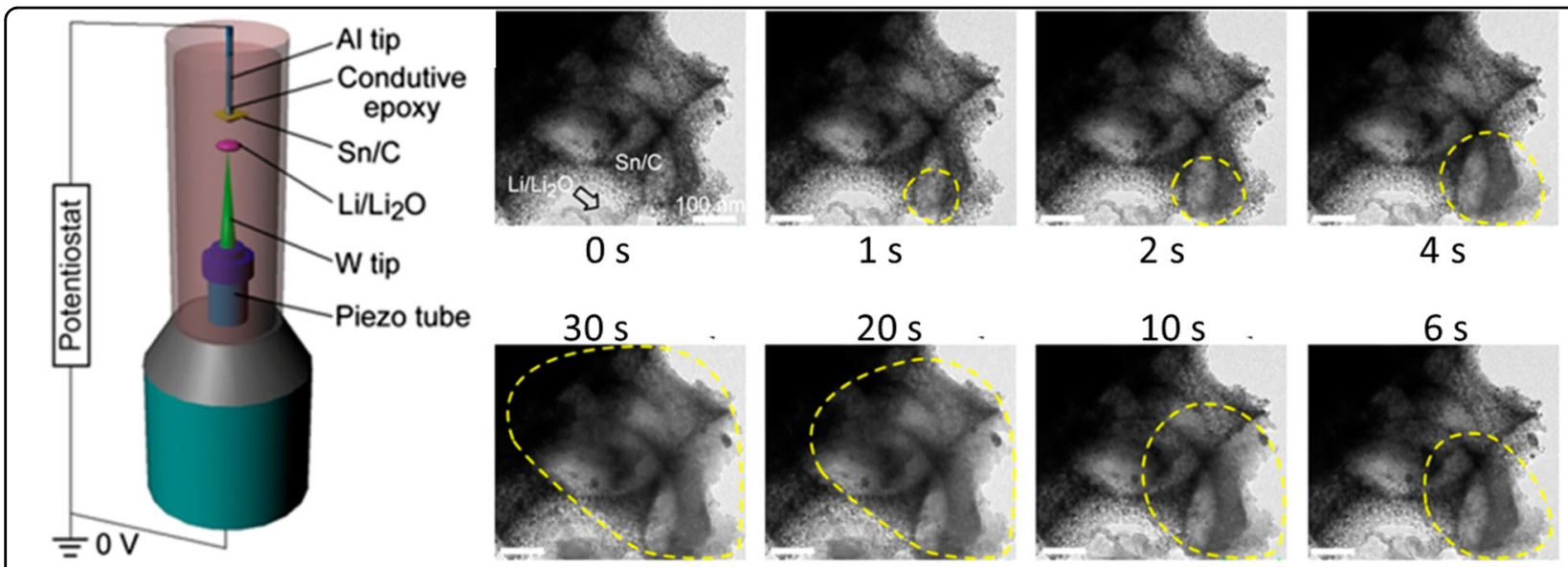

Fig. 4 In situ transmission electron microscopic observations of the three-dimensional ordered porous Sn/C anode during the lithiation process (modified from ref. ${ }^{58}$, copyright permission from the American Chemical Society)

addition, the $\mathrm{Si}$ anode has relatively low electronic conductivity. The Ni scaffold inside the structure can increase the electronic conductivity of the whole electrode ${ }^{66}$. In the case of these 3DOP $\mathrm{Si} / \mathrm{Ni}$ anodes, the capacity decrease is still obvious even though it was claimed that the 3DOP Ni inverse opal structure effectively accommodated volume changes of Si. Finite element (FE) analysis coupled with the experimental results was applied to investigate the $\mathrm{Li}$ ion diffusion-induced volume change and the corresponding mechanical damage of Si-coated Ni inverse opal structures $^{67}$. After comparing the numerical results for strains with prior in operando X-ray diffraction (XRD)based strain experimental data ${ }^{68}$, the FE approach verifies the feasibility of predicting the mechanical behavior of the $3 \mathrm{D} \mathrm{Si} / \mathrm{Ni}$ anode. Specifically, FE modeling is based on the 3D Ni scaffold with a pore size of $500 \mathrm{~nm}$ and coated with a 30-nm-thick Si active layer (Fig. 5a). Then this model is reduced to an one eighth subshell as the representative volume element of the Si-coated Ni inverse opal electrode. Finally, the Si and Ni structures are divided into 9063 and 696 tetrahedral elements, respectively, for computing mechanical deformation and diffusion during (de)lithiation (Fig. 5b). The Li concentration changes linearly during the (de)lithiation process, and the $\mathrm{Li}$ ion diffuses into/out of the $\mathrm{Si}$ according to the different $\mathrm{Li}$ concentration gradients. Through simulation, there is remaining $\mathrm{Li}$ concentration, with $1.22 \mathrm{~mol} \mathrm{Li}$ per mole of $\mathrm{Si}$ after the first lithiation-delithiation cycle, which causes 95\% volume expansion compared to the original electrode. This high volume change then leads to strains between the Si and Ni. Specifically, the Si active layer expands toward the pores and the scaffold during lithiation, and the expansion of Si toward the scaffold is constrained by the Ni scaffold, which puts the Ni scaffold under compression. By predicting plastic deformation in the Ni scaffold during lithiation, as shown in Fig. 5c, a stress gradient between the nodes and struts is demonstrated because the stress developed in the struts is higher than that in the nodes during (de)lithiation ${ }^{67}$, which thus causes mechanical degradation of the electrode after numerous lithiation cycles.

Other electrochemically active anode materials, such as graphene ${ }^{69}, \mathrm{TiNb}_{2} \mathrm{O}_{7}{ }^{70}, \mathrm{MoS}_{2}{ }^{71}, \mathrm{Ge}^{72,73}$, and $\mathrm{GeO}_{2}{ }^{74}$, were also designed to be 3DOP electrodes for $\mathrm{Li}$ ion storage. Few-layer graphene nanosheets tend to aggregate or restack owing to the strong van der Waals interactions, leading to large interface resistance and impeding highrate electronic conductivity ${ }^{75}$. A synergistic effect of structure and doping in the 3DOP graphene anode was demonstrated for ultrafast $\mathrm{Li}$ ion storage with long-term cycling ${ }^{69}$. 3DOP graphene with nitrogen $(\mathrm{N})$ and sulfur $(\mathrm{S})$ codoping was obtained through pyrolysis of the assembled graphene oxides and sulfonated polystyrene (S-PS) into a $3 \mathrm{D}$ continuous structure with the assistance of the surfactant of polyvinylpyrrolidone (PVP) ${ }^{69} . \mathrm{N}$ atoms from PVP and S atoms from S-PS were successfully doped in situ into the graphene nanosheets. This 3DOP N/S codoping graphene electrode exhibits a high specific capacity of $860 \mathrm{mAhg}^{-1}$ at $0.5 \mathrm{Ag}^{-1}$. The reversible capacities still can reach a high value of $220 \mathrm{mAh} \mathrm{g}^{-1}$ even at an ultrahigh current density of $80 \mathrm{~A} \mathrm{~g}^{-1}$, corresponding to a charge time of $10 \mathrm{~s}$. The $\mathrm{N}$ and $\mathrm{S}$ doping effects result in extrinsic defects in the basal plane of graphene. Li ions may diffuse into the interlayer space of graphene sheets through these extrinsic defects ${ }^{69}$. The special 3DOP structure combined with the heteroatom doping effect enables the as-prepared graphene electrodes with supercapacitor-like fast rate capabilities while maintaining battery-like high capacities. Certainly, the achieved ultrafast charge ability from the laboratory-scale half-cell 


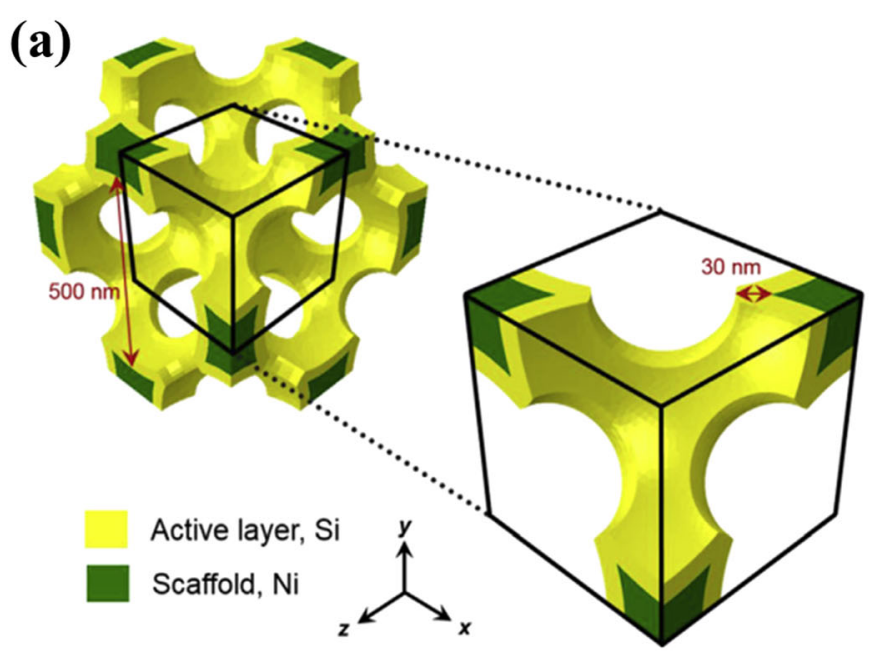

\section{(b)}

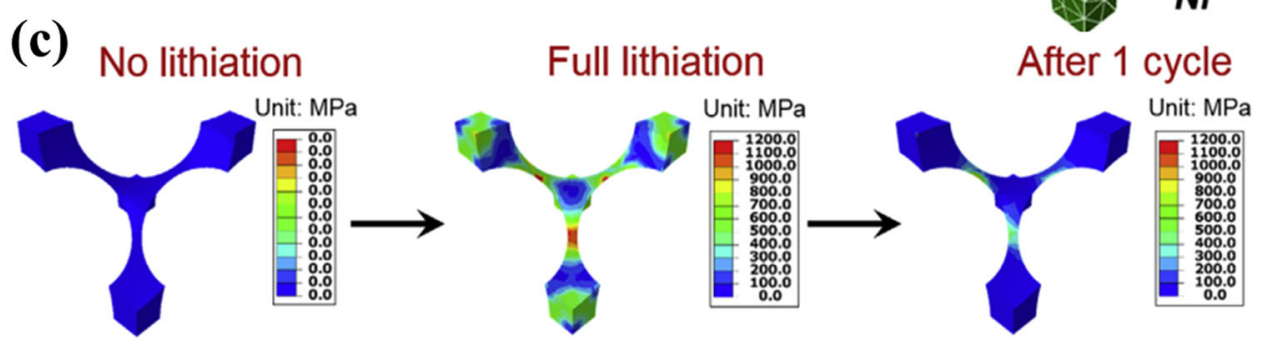

Fig. 5 Finite element modeling of the Si-coated three-dimensional ordered porous $\mathrm{Ni}$ electrode and the related stress distributions of the 3DOP Ni scaffold. a The Ni scaffold with a pore size of $500 \mathrm{~nm}$ and coated with a 30-nm thick Si active layer and the representative volume element (RVE) used in the finite element model. $\mathbf{b}$ The 3D mesh systems of the Si active layer and the Ni scaffold. c Computed stress distributions of the Ni scaffold at the initial point, after full lithiation (end of first half-cycle), and at the end of the first cycle (modified from ref. ${ }^{67}$, copyright permission from Elsevier)

tests is not directly equivalent to the high-rate capability of the actual industrial batteries.

In terms of the supercapacitor-like ultrafast rate capability, electrode materials with intercalation capacitances should be the best choice for charge-discharge processes on the order of minutes or even seconds ${ }^{76-78}$. 3DOP $\mathrm{TiNb}_{2} \mathrm{O}_{7}$ composed of interconnected single-crystalline nanoparticles exhibits the characteristics of $\mathrm{Li}$ ion pseudocapacitive storage ${ }^{70}$. The proportion of surfacecapacitance-controlled capacity is determined to be $51 \%$ and $79 \%$ at $0.05-1 \mathrm{mV} \mathrm{s}^{-1}$ (Fig. 6a, b), respectively. The diffusion-controlled charge is mainly generated near the peak voltage. The unique 3DOP architecture composed of interconnected nanocrystals provides enhanced capacitive charge storage, thus leading to good rate capability. As a typical layered transition-metal sulfide, $\mathrm{MoS}_{2}$ has a structure analogous to that of graphite, in which hexagonal layers of Mo are sandwiched between the two $S$ layers. S-Mo-S layers are held together by van der Waals forces, and the larger interlayer spacing $(0.62 \mathrm{~nm})$ provides ideal channels for the diffusion of $\mathrm{Li}$ ions as well as the transportation of electrons ${ }^{79,80}$. 3DOP $\mathrm{MoS}_{2} / \mathrm{C}$ was assembled in situ on carbon cloth (CC), in which the surface of each carbon fiber was composed of 3D interconnected ordered macroporous few-layered $\mathrm{MoS}_{2} / \mathrm{C}$ nanosheets ${ }^{71}$. The content of $\mathrm{MoS}_{2}$ nanosheets in the $\mathrm{MoS}_{2} / \mathrm{C} / \mathrm{CC}$ hybrids was measured to be approximately $55 \%$. It delivers a high discharge areal capacity of $3.802 \mathrm{mAh} \mathrm{cm}^{-2}\left(1130 \mathrm{mAh} \mathrm{g}^{-1}\right)$ at $0.1 \mathrm{~mA} \mathrm{~cm}^{-2}$. Quantum density functional theory calculations reveal that the $\mathrm{Li}$ ion binding energy on the (100) facet of $\mathrm{MoS}_{2}$ is stronger than those on the other facets. This suggests that exposing more (100) surfaces should be more beneficial for enhancing the specific capacity and rate capability of the $\mathrm{MoS}_{2}$ anode. Moreover, the edge-enriched ultrasmall few-layer $\mathrm{MoS}_{2}$ nanosheets with a lateral dimension of $5-10 \mathrm{~nm}$ are homogeneously incorporated into the 3DOP carbon wall, avoiding the restacking of $\mathrm{MoS}_{2}$ and exposing more active (100) facets ${ }^{71}$.

Germanium can reversibly react with $\mathrm{Li}$ ions, forming the $\mathrm{Li}_{4.4} \mathrm{Ge}$ alloy with a high theoretical capacity of 1638 $\mathrm{mAh} \mathrm{g}^{-1}$. Moreover, at room temperature, the Ge anode presents faster $\mathrm{Li}$ ion diffusivity (with diffusion coefficients of $4.55 \times 10^{-5} \mathrm{~cm}^{2} \mathrm{~s}^{-1}$ for Ge and $7.61 \times 10^{-6} \mathrm{~cm}^{2}$ $\mathrm{s}^{-1}$ for $\mathrm{Si}$ ) and is comparatively closer to the conductor than the $\mathrm{Si}$ anode (with band gaps of $0.66 \mathrm{eV}$ for Ge and 

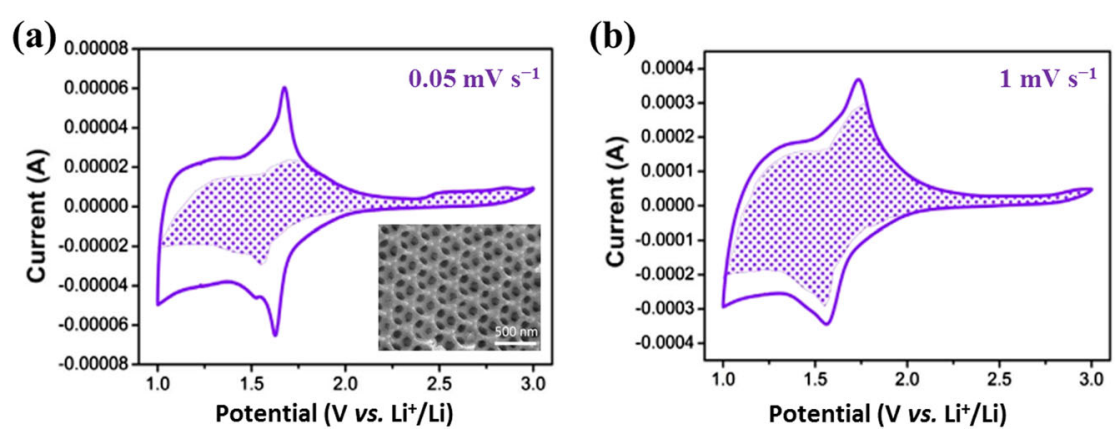

Fig. 6 The three-dimensional ordered porous (3DOP) structure enhances the intercalation capacitance in a $\mathrm{TiNb}_{2} \mathrm{O}_{7}$ electrode for $\mathrm{Li}$ ion storage. Cyclic voltammetric curves with separation between the total current (solid line) and capacitive currents (shaded regions) at a $0.05 \mathrm{mV} \mathrm{s}^{-1}$ and $\mathbf{b} 1 \mathrm{mV} \mathrm{s}^{-1}$. The inset is the scanning electron microscopicM image of the 3DOP $\mathrm{TiNb}_{2} \mathrm{O}_{7}$ electrode (modified from ref. ${ }^{70}$, copyright permission from Elsevier)

$1.11 \mathrm{eV}$ for $\mathrm{Si})^{81}$. However, similar to the $\mathrm{Si}$ anode, the $\mathrm{Ge}$ electrode undergoes a drastic volume change during the alloying-dealloying process, leading to rapid capacity fading. 3DOP Ge electrodes were prepared via ionic liquid (IL) electrodeposition directly onto ITO and copper substrates followed by the PS template etching process ${ }^{72}$. The 3DOP Ge electrode displays a much lower chargetransfer resistance than the dense Ge electrode. The initial discharge- and charge-specific capacities of 3DOP Ge are 1748 and $1024 \mathrm{mAh} \mathrm{g}^{-1}$, respectively. After 50 cycles, this material still retains a very high reversible capacity of $844 \mathrm{mAh} \mathrm{g}^{-1}$. The whole 3DOP structure is swollen with a rough surface, but no evident crack formation is observed $^{73}$. Even with high Li ion storage capacity and satisfactory cycling stability, the scarcity and high cost of Ge compared to the other metal alloy anodes may still hinder its further large-scale application.

\section{Cathode materials}

Research on commercial cathode materials in $\mathrm{Li}$ ion batteries is mainly focused on $\mathrm{LiCoO}_{2}$ and $\mathrm{LiFePO}_{4}$. $\mathrm{LiCoO}_{2}$ is the first commercialized cathode material with a redox potential of approximately $4.0 \mathrm{~V}\left(\mathrm{vs} . \mathrm{Li}^{+} / \mathrm{Li}\right)$ and a practical specific capacity of $140 \mathrm{mAhg}^{-1}$, with the amount of lithium, $x$, in $\mathrm{Li}_{1-x} \mathrm{CoO}_{2}$ usually below $0.5^{82}$. Overdelithiation would lead to a hexagonal phase transition from a monoclinic phase, leading to an abrupt shrinkage along the $c$ axis direction and cation disorder ${ }^{83,84}$. The olivine-structured $\mathrm{LiFePO}_{4}$ is considered the most likely promising alternative for $\mathrm{LiCoO}_{2}$ because of its large theoretical capacity $\left(172 \mathrm{mAh} \mathrm{g}^{-1}\right)$, low cost, and environmental benignancy ${ }^{85,86}$. Its main disadvantage is its poor conductivity and rate capability ${ }^{87}$. To overcome the low electronic conductivity, the $\mathrm{LiFePO}_{4}$ electrode is usually coated with conductive agents.

Early studies on the 3DOP $\mathrm{LiCoO}_{2}$ cathode revealed that the 3DOP structure may improve its specific discharge capacities at higher current rates but cause poor cyclability because the contraction/swelling of the small particles in the 3DOP walls during cycling leads to particle disconnections ${ }^{88}$. The poor cycling stability is more serious for the 3DOP $\mathrm{LiCoO}_{2}$ cathode synthesized at lower calcining temperatures ${ }^{89}$. The $3 \mathrm{DOP} \mathrm{LiCoO}_{2}$ calcined at $700{ }^{\circ} \mathrm{C}$ presents a better crystal framework with a typical inverse opal structure. It displays a specific discharge capacity of $151 \mathrm{mAh} \mathrm{g}^{-1}$ at a current density of $1 \mathrm{C}$, which is higher than that of commercial $\mathrm{LiCoO}_{2}$. Moreover, $92 \%$ of the specific discharge capacity is retained after 50 cycles. Hierarchical $3 \mathrm{DOP} \mathrm{LiFePO}_{4} /$ carbon composites with macroporosity/mesoporosity/ microporosity were synthesized via a multiconstituent and dual-templating method ${ }^{90}$. These composites exhibit a specific capacity of $150 \mathrm{mAh} \mathrm{g}^{-1}$. When the current density increases to $16 \mathrm{C}$, there is still a capacity of approximately $65 \mathrm{mAh} \mathrm{g}^{-1}$. Using colloidal crystal spheres with different diameters of 100,140 , and $270 \mathrm{~nm}$, three types of $3 \mathrm{DOP} \mathrm{LiFePO}_{4}$ samples were produced ${ }^{91}$. The 3DOP $\mathrm{LiFePO}_{4}$ with a $270-\mathrm{nm}$ colloidal crystal template displays both high surface area and improved electrolyte access and hence has the highest discharge capacity. In addition, the smaller colloidal crystal template $(100 \mathrm{~nm})$ produces an excess amount of residual carbon in the obtained $\mathrm{LiFePO}_{4}$ sample. Although the addition of carbon to the $\mathrm{LiFePO}_{4}$ electrode can improve the conductivity and overall electrochemical performance, excess carbon in the $\mathrm{LiFePO}_{4}$ electrode would prevent the electrolyte from fully infiltrating into the pores at the center of the $\mathrm{LiFePO}_{4}$ particles.

$\mathrm{LiMnO}_{2}$ has attracted extensive interest owing to its high theoretical capacity of $285 \mathrm{mAh} \mathrm{g}^{-1}$ and realistic capacity of up to $200 \mathrm{mAhg}^{-192}$. The $\mathrm{LiMnO}_{2}$ crystal possesses a layered monoclinic structure and orthorhombic structure with a zigzag arrangement of $\mathrm{Li}$ and $\mathrm{Mn}$. Current studies on $\mathrm{LiMnO}_{2}$ mainly focus on the orthorhombic phase because the monoclinic phase is very difficult to synthesize ${ }^{93,94}$. To obtain 3DOP $\mathrm{LiMnO}_{2}, \mathrm{MnO}_{2}$ 
was electrodeposited into the 3DOP Ni framework and subsequently lithiated in a molten salt ${ }^{95}$. The 3DOP $\mathrm{LiMnO}_{2}$ electrode with a thickness of $30 \mathrm{~nm}$ exhibits a high specific capacity of $198 \mathrm{mAh} \mathrm{g}^{-1}$. Even when discharged at $185 \mathrm{C}$, it still retains a specific capacity of $75 \mathrm{mAh} \mathrm{g}^{-1}$, approximately $38 \%$ of its initial capacity (Fig. 7a). The 3DOP $\mathrm{LiMnO}_{2} / \mathrm{Ni}$ electrode provides both fast ion and electron transport in the electrolyte, electrode, and current collector. Recently, the fast-growing popularity of microelectronics has required the continuous development of miniaturized power sources. In this background, $\mathrm{Li}$ ion microbatteries based on 3DOP interdigitated $\mathrm{LiMnO}_{2}$ microelectrodes are reported using an electrodeposition method on the interdigitated gold current collector (Fig. 7b). The interdigitated electrodes have a width of $30 \mathrm{~mm}$ and a spacing of $10 \mathrm{~mm}$ (Fig. 7c). This Li ion microbattery displays an energy density of $2.5 \mu \mathrm{Wh} \mathrm{cm}^{-2} \mu \mathrm{m}^{-1}$ at $0.5 \mathrm{C}$. It still retains $28 \%$ of its original energy even at $1000 C^{96}$. The high-power delivery is the largest advantage of the Li ion microbattery based on 3DOP electrode materials. Another Li ion microbattery with $3 \mathrm{DOP} \mathrm{LiMnO}_{2}$ as a cathode and $3 \mathrm{DOP} \mathrm{Ni}-\mathrm{Sn}$ alloy as an anode was fabricated by $3 \mathrm{D}$ holographic lithography and conventional photolithography, followed by template-assisted electrodeposition ${ }^{97}$. The resultant microbattery exhibits a volumetric energy density of 4.5 and $0.6 \mu \mathrm{Wh} \mathrm{cm}^{-2} \mu \mathrm{m}^{-1}$ at 1 and $1000 \mathrm{C}$, respectively. For practical applications, a conventional light-emitting diode is driven with a $500-\mu \mathrm{A}$ peak current $(600 \mathrm{C}$ discharge) from the abovementioned microbattery with a thickness of $10 \mu \mathrm{m}$. After 200 cycles, this microbattery still presents an output current of $440 \mu \mathrm{A}$ with only $12 \%$ capacity fade (Fig. 7d). The volumetric energy and power of the microbattery show a strong correlation with the structural parameters of the interdigitated electrodes, such as porosity, shape, digit width, and porosity. Certainly, for miniaturized electronics, the volumetric energy and power densities are less important than areal ones ${ }^{98}$. However, the abovementioned Li ion microbattery still has relatively low areal energy densities owing to the limited electrode thicknesses.

As alternatives of phosphates (i.e., $\mathrm{LiFePO}_{4}$ ), silicates (i.e., $\mathrm{Li}_{2} \mathrm{FeSiO}_{4}$ ) have attracted significant interest for next-generation $\mathrm{Li}$ ion batteries in recent years. The lower electronegativity of $\mathrm{Si}$ (2.03) than of P (2.39) would reduce the electronic band gap and increase the electronic transport. Importantly, $\mathrm{Li}_{2} \mathrm{FeSiO}_{4}$ can supply a high theoretical capacity of up to $331 \mathrm{mAh} \mathrm{g}^{-1}$ through a potential two-electron transfer reaction. In addition, the earthabundant elements $\mathrm{Fe}$ and $\mathrm{Si}$ are cost-effective and scalable resources ${ }^{99-101}$. Recently, a 3DOP $\mathrm{Li}_{2} \mathrm{FeSiO}_{4} / \mathrm{C}$ composite was prepared via a "hard-soft" templating method ${ }^{102,103}$. The 3DOP $\mathrm{Li}_{2} \mathrm{FeSiO}_{4} / \mathrm{C}$ cathode exhibits a high reversible capacity of $239 \mathrm{mAhg}^{-1}$ and superior long-term cycling stability with a capacity retention of nearly $100 \%$ over 400 cycles $^{102}$. The calculated $\mathrm{Li}^{+}$ion diffusion coefficients in the 3DOP $\mathrm{Li}_{2} \mathrm{FeSiO}_{4} / \mathrm{CF}$ (carbon nanofiber) and bulk $\mathrm{Li}_{2} \mathrm{FeSiO}_{4} / \mathrm{CF}$ were $7.62 \times 10^{-13}$ and $4.54 \times 10^{-13} \mathrm{~cm}^{2} \mathrm{~s}^{-1}$, respectively ${ }^{103}$. The ordered macropores create a short $\mathrm{Li}$ ion diffusion pathway and accommodate volumetric changes, while the carbon matrix serves as a conductive network to improve the electron transport of $\mathrm{Li}_{2} \mathrm{FeSiO}_{4}$.

$\mathrm{Li}_{3} \mathrm{~V}_{2}\left(\mathrm{PO}_{4}\right)_{3}$ possesses a high redox potential $(3.8 \mathrm{~V}$ vs. $\left.\mathrm{Li}^{+} / \mathrm{Li}\right)$ and a relatively high theoretical specific capacity $\left(197 \mathrm{mAh} \mathrm{g}^{-1}\right)^{104}$. Furthermore, monoclinic $\mathrm{Li}_{3} \mathrm{~V}_{2}\left(\mathrm{PO}_{4}\right)_{3}$ with a sodium superionic conductor (NASICON) structure provides a very high ion diffusion coefficient (from $10^{-9}$ to $10^{-10} \mathrm{~cm}^{2} \mathrm{~s}^{-1}$ ). However, it suffers from a low electronic conductivity $\left(2.3 \times 10^{-8} \mathrm{~S} \mathrm{~cm}^{-1}\right)$, which limits its practical application ${ }^{105}$. Carbon-coated 3DOP $\mathrm{Li}_{3} \mathrm{~V}_{2}\left(\mathrm{PO}_{4}\right)_{3}$ was successfully synthesized by a simple onepot procedure ${ }^{106}$. This 3DOP $\mathrm{Li}_{3} \mathrm{~V}_{2}\left(\mathrm{PO}_{4}\right)_{3} / \mathrm{C}$ cathode displays a significantly improved rate capability relative to that of the corresponding bulk nanocomposite. After 60 cycles, a high reversible capacity of $148 \mathrm{mAhg}^{-1}$ is retained at $2 \mathrm{C}$ with a capacity loss of only $0.08 \%$ per cycle. To further improve the electronic conductivity of $\mathrm{Li}_{3} \mathrm{~V}_{2}\left(\mathrm{PO}_{4}\right)_{3}$, a series of $\mathrm{Ce}^{3+}$-doped 3DOP $\mathrm{Li}_{3} \mathrm{~V}_{2-}$ ${ }_{x} \mathrm{Ce}_{x}\left(\mathrm{PO}_{4}\right)_{3} / \mathrm{C}$ materials $(x=0,0.01,0.03,0.05)$ were obtained and evaluated as cathodes for $\mathrm{Li}$ ion batteries ${ }^{107}$. Doping of the Ce element does not affect the formation of a 3D ordered macroporous structure. The 3DOP $\mathrm{Li}_{3} \mathrm{~V}_{1.97} \mathrm{Ce}_{0.03}\left(\mathrm{PO}_{4}\right)_{3} / \mathrm{C}$ electrode has the best electrochemical behavior among the four samples. The radius of the $\mathrm{Ce}^{3+}$ ion is much larger than that of the $\mathrm{V}^{3+}$ ion. The unit cell volume of the $\mathrm{Li}_{3} \mathrm{~V}_{2}\left(\mathrm{PO}_{4}\right)_{3} / \mathrm{C}$ increases after an appropriate amount of $\mathrm{Ce}^{3+}$ doping. Such expansion in the crystal lattice may enhance the diffusion rate of $\mathrm{Li}^{+}$ ions into the $\mathrm{Li}_{3} \mathrm{~V}_{2}\left(\mathrm{PO}_{4}\right)_{3}$ lattice.

Recently, the electrochemical performance of a 3DOP $\mathrm{V}_{2} \mathrm{O}_{5}$ cathode was reported for $\mathrm{Li}$ ion storage ${ }^{108}$. The 3DOP $\mathrm{V}_{2} \mathrm{O}_{5}$ electrode presents a series of discrete redox peaks. The subsequent $\mathrm{CV}$ curve cycles for the 3DOP $\mathrm{V}_{2} \mathrm{O}_{5}$ electrode are much smoother than the initial cycles because of the formation of an irreversible $\omega-\mathrm{Li}_{2+x} \mathrm{~V}_{2} \mathrm{O}_{5}$ phase confirmed by ex situ Raman spectral studies ${ }^{108}$. Notably, the walls of the $3 \mathrm{DOP} \mathrm{V}_{2} \mathrm{O}_{5}$ structure became thicker after 100 cycles due to volume changes associated with lithiation. Additionally, some regions of the 3DOP $\mathrm{V}_{2} \mathrm{O}_{5}$ appeared pulverized. Thus the 3DOP $\mathrm{V}_{2} \mathrm{O}_{5}$ electrode on the stainless steel current collector displays a significant fading from an initial capacity of 151-51 mAh $\mathrm{g}^{-1}$ after 100 cycles. When using FTO-coated glass as a current collector, it exhibits improved cyclability with a specific capacity of $\sim 191 \mathrm{mAh} \mathrm{g}^{-1}$ after 75 cycles $^{108}$. Then graphene-wrapped 3DOP $\mathrm{V}_{2} \mathrm{O}_{5}$ was demonstrated to further improve the cycling stability ${ }^{109}$. The electrically 
(a)

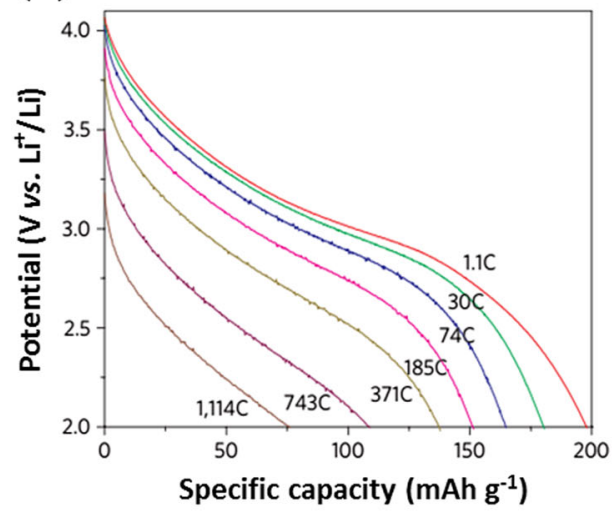

(c)

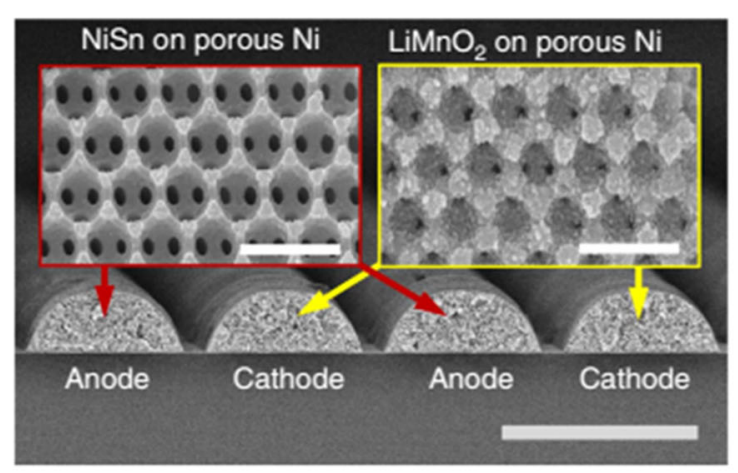

(b)

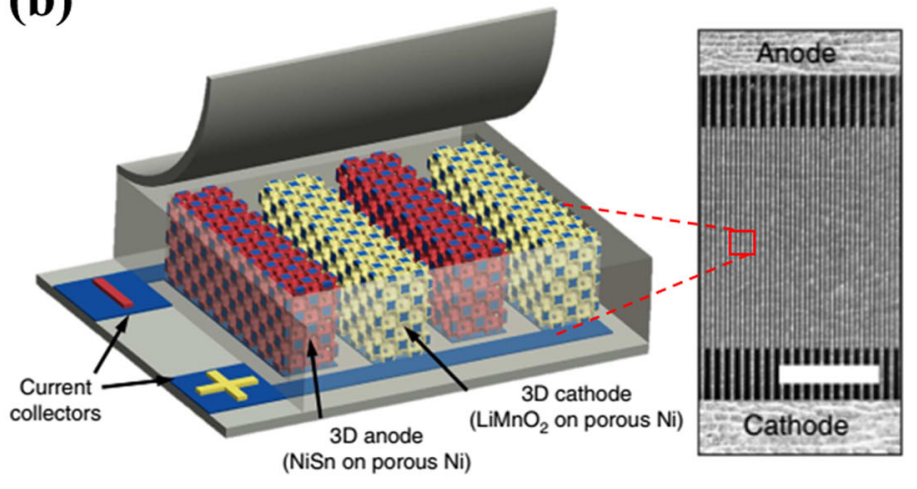

(d)

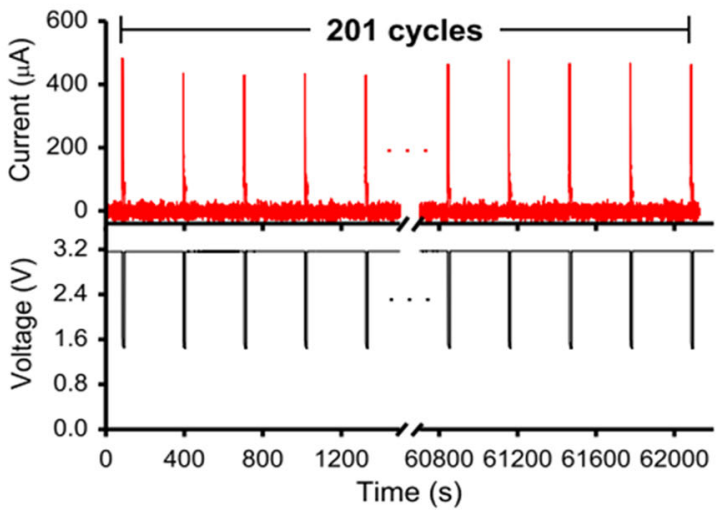

Fig. 7 The Li ion microbattery based on three-dimensional ordered porous (3DOP) electrodes. a The ultrafast discharge of the 3DOP LiMnO 2 cathode. $\mathbf{b}$ Schematic illustration of the Li ion microbattery containing a 3DOM LiMnO${ }_{2}$ cathode and a 3DOP NiSn alloy anode with the top-down scanning electron microscopic (SEM) image of the interdigitated electrodes. Scale bar, $500 \mathrm{~mm}$. c SEM cross-section of the interdigitated electrodes. Scale bars, 50 and $1 \mathrm{~mm}$ in the insets. $\mathbf{d}$ Current and voltage profiles of the microbattery that is controlled by a single-pole-double-throw (SPDT) relay to periodically power a red light-emitting diode for $10 \mathrm{~s}$ and is charged with two AA batteries for 5 min (modified from ref. ${ }^{96}$, Copyright permission from Nature Publishing Group)

conductive graphene nanosheets with thicknesses of 4-10 layers are embedded into two thick layers of $\mathrm{V}_{2} \mathrm{O}_{5}$. The resultant 3DOP $\mathrm{V}_{2} \mathrm{O}_{5} /$ graphene $/ \mathrm{V}_{2} \mathrm{O}_{5}$ electrode exhibits a capacity of approximately $198 \mathrm{mAh} \mathrm{g}^{-1}$ over 1000 cycles. In addition, the 3DOP graphene embedded inside the $\mathrm{V}_{2} \mathrm{O}_{5}$ cathode enables good electronic conductivity for fast electron transportation. This is essential for highperformance $\mathrm{V}_{2} \mathrm{O}_{5}$ electrodes because of their poor electronic conductivity. Interestingly, a symmetric microbattery based on the $\mathrm{V}_{2} \mathrm{O}_{5}$ film was confined within 3DOP anodic aluminum oxide (AAO) microchannels ${ }^{110}$. By using the atomic layer deposition, a 7.5-nm-thick Ru layer as the current collector and a 23-nm-thick $\mathrm{V}_{2} \mathrm{O}_{5}$ film as the active material were conformably coated on AAO nanotube arrays. $\mathrm{V}_{2} \mathrm{O}_{5}$ on one side was prelithiated to serve as the anode, and the pristine $\mathrm{V}_{2} \mathrm{O}_{5}$ film on the other side was used as the cathode. In 3DOP microchannel templates, the $\mathrm{V}_{2} \mathrm{O}_{5}$ electrodes tended to expand upon lithiation and form uniform structures within the microchannels over repeated cycles. This may prevent thin-film active materials from falling off from the electrodes during the cycles, thus achieving a long-term cycle lifespan of up to 1000 cycles. In addition to the improved cycling stability, the enhanced kinetics of the Li ion insertion reaction is demonstrated in the interconnected 3DOP $\mathrm{V}_{2} \mathrm{O}_{5}$ electrodes ${ }^{111}$, which are associated with the enhancement in Faradaic reaction utilization of both the surface-dominant and the bulk diffusion-dominant reactions. Moreover, the symmetric $\mathrm{V}_{2} \mathrm{O}_{5}$ microbattery with a low voltage can be easily extended to a $\mathrm{V}_{2} \mathrm{O}_{5}-\mathrm{SnO}_{2}$ asymmetric microbattery with a high voltage ${ }^{112}$.

Iron trifluoride $\left(\mathrm{FeF}_{3}\right)$ is considered another promising cathode material due to its high theoretical capacity of 
$237 \mathrm{mAh} \mathrm{g}^{-1}$ (1-e transfer) and $712 \mathrm{mAh} \mathrm{g}^{-1}$ (3-e transfer ${ }^{113}$. Poly(3,4-ethylene dioxythiophene) (PEDOT) was coated on the 3DOP $\mathrm{FeF}_{3}$ electrode by an in situ polymerization method ${ }^{114}$. The $3 \mathrm{DOP} \mathrm{FeF}_{3}$ electrode without a conducting PEDOT coating shows a specific capacity of $148 \mathrm{mAh} \mathrm{g}^{-1}$, which is much lower than that of 3DOP $\mathrm{FeF}_{3}$-PEDOT $\left(210 \mathrm{mAh} \mathrm{g}^{-1}\right)$. The homogeneous coating of conductive polymer greatly improves the conductivity of the 3DOP $\mathrm{FeF}_{3}$ electrode. However, the commercial nonporous $\mathrm{FeF}_{3}$ electrode coated by conducting PEDOT displays only a capacity of $105 \mathrm{mAh} \mathrm{g}^{-1}$. This result suggests that the conductivity is not the only key factor and that the 3DOP structure also plays a key role in improving the electrochemical performance of the $\mathrm{FeF}_{3}$ cathode.

\section{DOP electrode materials for use in aqueous rechargeable lithium batteries (ARLBs)}

ARLBs are one of the most promising alternatives for large-scale applications due to their advantages of safety, low cost, superfast charge ability, and environmental friendliness. As the most commonly used cathode in ARLBs, spinel-type $\mathrm{LiMn}_{2} \mathrm{O}_{4}$ has attracted increasing interest for both fundamental and practical applications. In a neutral aqueous electrolyte, the 3DOP $\mathrm{LiMn}_{2} \mathrm{O}_{4}$ electrode exhibits a capacity retention of $93 \%$ after 10,000 cycles (Fig. 8a) ${ }^{115}$. The capacity of the bulk $\mathrm{LiMn}_{2} \mathrm{O}_{4}$ electrode rapidly decreases over 2000 cycles. The ordered macroporous structure can accommodate some strain/ stress during the charge and discharge process, which is demonstrated via the changes of the XRD patterns of the 3DOP and bulk $\mathrm{LiMn}_{2} \mathrm{O}_{4}$ electrodes prior to cycling and after 10,000 cycles $^{115}$.

$3 \mathrm{DOP} \mathrm{LiFePO}_{4}$ coated with carbon and interwoven with multiwall carbon nanotubes (CNTs) also exhibits a superfast capability in $0.5 \mathrm{M} \mathrm{Li}_{2} \mathrm{SO}_{4}$ aqueous electrolyte ${ }^{116}$. Even at charging rates of $120 \mathrm{C}(30 \mathrm{~s}), 300 \mathrm{C}$ (12 s), and $600 \mathrm{C}(6 \mathrm{~s})$, specific discharge capacities still remain at 97, 84, and $62 \mathrm{mAh} \mathrm{g}^{-1}$, respectively (Fig. 8b). The charging/discharging rate of $3 \mathrm{DOP} \mathrm{LiFePO}_{4}$ in an aqueous electrolyte is much higher than that in nonaqueous electrolytes by nearly five times. Ab initio calculations indicate that a special solid/liquid interface forms at the $\mathrm{LiFePO}_{4}$ surface, which lowers the energy barriers of the $\mathrm{Li}^{+}$-desolvation process and enables fast $\mathrm{Li}$ ion transport across the solid/liquid interfaces. To further improve the operating voltage and energy density of ARLBs, a new generation of aqueous rechargeable batteries is built using a coated $\mathrm{Li}$ metal as an anode and $3 \mathrm{DOP} \mathrm{LiFePO}_{4}$ as a cathode, whose average discharge voltage can reach 3.30 $\mathrm{V}^{117}$. The lithium metal used was first coated with a gel polymer electrolyte (GPE) with an ionic conductivity on the order of $10^{-4} \mathrm{~S} \mathrm{~cm}^{-1}$. Then a LISICON film (solid fast $\mathrm{Li}$ ion conductor) was further placed on the surface of GPE. The LISICON film allows only the Li ions to pass through for the charge balance. The GPE acts as a buffer to endure the volume change of Li metal and prevent the reaction between lithium metal and the LISICON film. More importantly, the formation of lithium dendrites will be suppressed because the GPE has higher viscosity than the organic liquid electrolytes. Since both the coated $\mathrm{Li}$ anode and the 3DOP $\mathrm{LiFePO}_{4}$ are stable in the aqueous electrolyte for reversible redox reactions, the fabricated ARLB exhibits an excellent cycling life with a Coulombic efficiency of nearly $100 \%{ }^{117}$.

\section{DOP electrode materials for use in Li-S batteries}

Li-S batteries should be one of the most promising next-generation electrochemical energy storage devices because they have a high specific capacity of $1672 \mathrm{mAh}$ $\mathrm{g}^{-1}$ and an energy density of $2600 \mathrm{Wh} \mathrm{kg}^{-1}$ (including the mass of the $\mathrm{Li}$ anode), which are three to five times higher than those of state-of-the-art Li-ion batteries ${ }^{118-120}$. A Li$\mathrm{S}$ battery is a highly complex system with two typical electrochemical reactions between lithium metal and elemental sulfur:

$$
\begin{aligned}
& S_{8}+L i^{+}+e^{-} \rightarrow L i_{2} S_{x}(2.4-2.1 V) \\
& L i_{2} S_{x}+L i^{+}+e^{-} \rightarrow L i_{2} S_{2} \text { and } / \text { or } L i_{2} S(2.1-1.5 V)
\end{aligned}
$$

Many significant issues resulting from both the sulfur cathode and the lithium metal anode hinder their practical application, including the poor electrical conductivities of sulfur and $\mathrm{Li}_{2} \mathrm{~S}$, the large volume expansion over the reversible transformation between sulfur and $\mathrm{Li}_{2} \mathrm{~S}$, the dissolution of lithium polysulfides (such as $\mathrm{Li}_{2} \mathrm{~S}_{8}$, $\mathrm{Li}_{2} \mathrm{~S}_{6}, \mathrm{Li}_{2} \mathrm{~S}_{4}$ ), and the instability and dendrite growth of $\mathrm{Li}$ metal anodes. Intensive efforts have been devoted to the rational design of the electrode structure to address the abovementioned issues ${ }^{121}$. To alleviate the problem of extremely low conductivity and large volume expansion of the sulfur cathodes upon cycling, an effective method is the utilization of a 3DOP carbon as the substrate (or host) for the insulating sulfur electrode ${ }^{122}$. For example, a 3DOP carbon coupled with mesopores (3-6 nm) can act as a framework to encapsulate the intermediate products and restrain the shuttle effect of lithium polysulfide ${ }^{123}$.

$\mathrm{N}$-doped 3DOP carbon is used as a host for sulfur cathodes in Li-S batteries ${ }^{124,125}$. The 3DOP N-doped C/S composite achieves an ultralong cycle life up to 500 cycles with a capacity decay as low as $0.057 \%$ per cycle ${ }^{124}$. Interestingly, $\mathrm{N}$ doping and 3DOP carbon work synergistically to further entrap the dissolvable polysulfides, hence enabling the immobilization of sulfur. To maximize the areal sulfur loading, the formation of a thick 3DOP Ndoped C/S composite was achieved with close-packed interconnected nanosphere clusters and high sulfur loading of up to $5 \mathrm{mg} \mathrm{cm}^{-2125}$. Such high areal sulfur loading is of commercial interest to replace current $\mathrm{Li}$ ion 

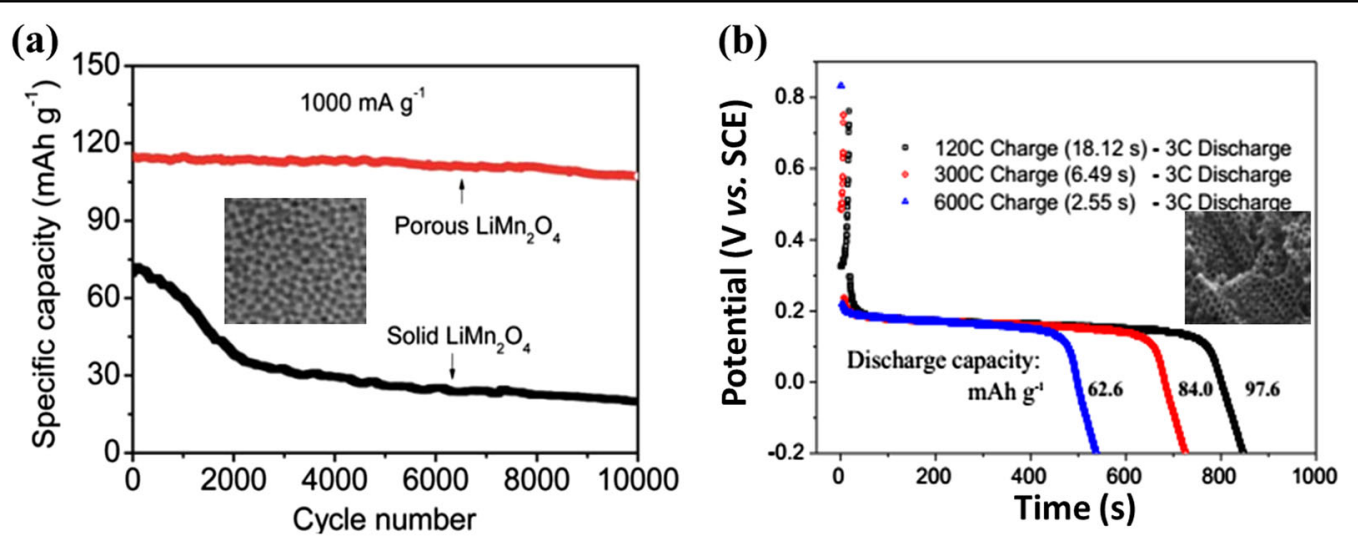

Fig. 8 The ultrahigh electrochemical performance of three-dimensional ordered porous (3DOP) electrodes in queous rechargeable lithium batteries. a The cycling behaviors of the solid and 3DOP $\mathrm{LiMn}_{2} \mathrm{O}_{4}$ electrodes. The inset is the scanning electron microscopic (SEM) image of the $3 \mathrm{DOP} \mathrm{LiMn}_{2} \mathrm{O}_{4}$ electrode (modified from ref. ${ }^{115}$, Copyright permission from the Royal Society of Chemistry). b Superfast charge performance of 3DOP $\mathrm{LiFePO}_{4}$ interwoven with multiwall carbon nanotubes (MWCNTs). The inset is the SEM image of the 3DOP $\mathrm{LiMn}_{2} \mathrm{O}_{4}$ electrode (modified from ref. ${ }^{116}$, Copyright permission from the American Chemical Society)

batteries. Nevertheless, the long-term lifespan is still unsatisfactory considering the low affinity of carbon materials for polysulfide species.

To increase the affinity of carbon hosts for polysulfide species, metals or metal oxides are introduced into the heteroatom-functionalized 3DOP carbon materials, which can further reduce the polysulfide shuttle issue and benefit the kinetics of polysulfide redox reactions ${ }^{126-128}$. Specifically, the novel two-in-one cobalt (Co)-embedded $\mathrm{N}$-doped mesoporous carbon nanosheets were fabricated as stable hosts for both sulfur cathodes and a metallic lithium anode. On the one hand, owing to the high electronic conductivity and excellent structural polarity for the polysulfide containment, the Co nanoparticles can work synergistically with $\mathrm{N}$ heteroatoms to promote the redox reaction kinetics and alleviate the polysulfide solubility, thus endowing the sulfur cathodes with an excellent rate capability and long lifetime of 400 cycles with a capacity decay of $<0.036 \%$ per cycle. On the other hand, the high surface area of the mesoporous structure and the $\mathrm{N}$ heteroatoms can regulate metallic lithium plating/stripping and hinder dendrite overgrowth, yielding lithium metal anodes with an excellent Coulombic efficiency of nearly $100 \%$ over 100 cycles $^{126}$. Interestingly, through the delicate incorporation of $\mathrm{ZrO}_{2}$ in holey CNTs/S electrodes, permselective gateways for $\mathrm{Li}$ ion transportation were realized at sufficient mesopore openings, which are impenetrable to lithium polysulfides ${ }^{127}$. In addition to the metal and metal oxides, B-, N-, or Odoped holey graphene also exhibits a distinguished ability to trap the polysulfides due to the strong polarto-polar interaction ${ }^{128}$.

3DOP carbon as a substrate for sulfur cathodes is then utilized to couple with room-temperature IL electrolytes to further improve the immobilization of lithium polysulfides ${ }^{129,130}$. The dissolution of $\mathrm{Li}_{2} \mathrm{~S}_{x}$ was efficiently suppressed in the electrolyte comprising $N$ butyl- $N$-methyl-piperidinium bis(trifluoromethanesulfonyl) amide $^{129}$. The weakly acidic/basic nature of the lithium bis (trifluoromethanesulfonyl)amide-tetraglyme complex electrolyte, may cause low coordination ability toward $\mathrm{Li}_{2} \mathrm{~S}_{x}$. In terms of some solvate ILs, polysulfides are insoluble and tend to form an inhomogeneous layer that covers the 3DOP carbon surface. In this case, the more suitable structure should be the 3DOP carbon with both large macropores and a large volume instead of the widely accepted mesopores and/or micropores that work well for conventional polysulfide-soluble electrolytes ${ }^{130}$. Unfortunately, the cost of the IL electrolyte may render them impractical and uneconomical for applications. In contrast, for traditional organic electrolytes, the bimodal micropores/mesopores of the 3DOP carbon materials are now the most popular materials for enhancing the confinement of dissoluble intermediate lithium polysulfides because of the combination of sulfur loading sites in micropores and the electrolyte reservoir (or channels) in mesopores to enhance the transportation of ions throughout the $\operatorname{architecture}^{131}$.

\section{DOP electrode materials for use in $\mathrm{Li}^{-} \mathrm{O}_{2}$ batteries}

Oxygen $\left(\mathrm{O}_{2}\right)$ as a cathode has received significant interest in the past decade since it provides a high ther-

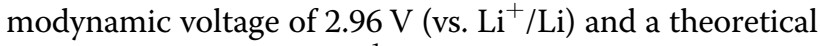
capacity of $1675 \mathrm{mAh} \mathrm{g}^{-1}$ with $\mathrm{Li}_{2} \mathrm{O}_{2}$ as the discharge product. When considering the total mass of $\mathrm{Li}$ (with a theoretical capacity of $3860 \mathrm{mAh} \mathrm{g}^{-1}$ ) and $\mathrm{O}_{2}$, the theoretical capacity of a $\mathrm{Li}_{-} \mathrm{O}_{2}$ battery is $1168 \mathrm{mAh} \mathrm{g}^{-1}$, with a corresponding theoretical specific energy density of 3460 $\mathrm{Wh} \mathrm{kg}^{-1}$. In a $\mathrm{Li}^{-\mathrm{O}_{2}}$ battery, the cathode functions as an 
oxygen reduction reaction (ORR) catalyst during discharge with the reduction of $\mathrm{O}_{2}$ as $2 \mathrm{Li}^{+}+\mathrm{O}_{2}+2 \mathrm{e}^{-} \rightarrow$ $\mathrm{Li}_{2} \mathrm{O}_{2}$ and hopefully works as an oxygen evolution reaction (OER) catalyst during charge with the electrochemical decomposition reaction of $\mathrm{Li}_{2} \mathrm{O}_{2}$ as $\mathrm{Li}_{2} \mathrm{O}_{2} \rightarrow$ $2 \mathrm{Li}^{+}+\mathrm{O}_{2}+2 \mathrm{e}^{-}$. Currently, the development of $\mathrm{Li}-\mathrm{O}_{2}$ batteries is encumbered with vast scientific and technological challenges, involving high charge/discharge overpotentials directly related to low energy efficiency, deposition of insulating $\mathrm{Li}_{2} \mathrm{O}_{2}$ product, poor stability of cathodes and electrolytes, and safety hazards associated with Li metal anodes. Most of these challenges are associated with the oxygen reactions occurring in the cathode. To realize the high energy density of $\mathrm{Li}-\mathrm{O}_{2}$ batteries, many research efforts have been devoted to designing suitable and effective cathode catalysts ${ }^{132-134}$. In fact, the performance of $\mathrm{Li}-\mathrm{O}_{2}$ batteries (such as discharge/charge overpotential, energy efficiency, cycle life) is closely related to the catalyst materials and the architecture of the catalyst electrodes ${ }^{135}$. Generally, an ideal catalyst electrode requires a highly conductive and porous structure to facilitate both electron and oxygen transport and provide sufficient space for the formed $\mathrm{Li}_{2} \mathrm{O}_{2}{ }^{136}$.

Porous network models were recently developed to simulate the electrochemical behaviors of $\mathrm{Li}-\mathrm{O}_{2}$ cathode mesostructures, which clearly demonstrate that 3DOP structures with rich interconnectivity and the microscopic arrangement of pores may lead to variations in electrochemical behaviors ${ }^{137}$. A composite based on a rock saltstructured $\left(\mathrm{Mn}_{1 / 3} \mathrm{Co}_{2 / 3}\right) \mathrm{O}$ catalyst and CNT microspheres was designed as an efficient cathode material for $\mathrm{Li}-\mathrm{O}_{2}$ batteries. The wetting of the electrolyte and the diffusion of oxygen are greatly facilitated within the macroporous structure of CNTs, which also provides enough space to accommodate $\mathrm{Li}_{2} \mathrm{O}_{2}$ species. Thus the 3DOP macroporous $\left(\mathrm{Mn}_{1 / 3} \mathrm{Co}_{2 / 3}\right) \mathrm{O}$-CNT composite microspheres serve as a highly efficient bifunctional catalysts with excellent ORR and OER activities ${ }^{138}$.

The 3D ordered macroporous/mesoporous carbon was synthesized using a dual-template method and then used as a catalyst for $\mathrm{Li}_{-} \mathrm{O}_{2}$ batteries ${ }^{139,140}$. The $\mathrm{O}_{2}$ catalytic cathode was obtained by coating a homogeneous mixture of the ordered macroporous/mesoporous carbon, carbon black, and a polyvinylidene fluoride binder (PVDF, $20 \mathrm{wt} \%$ ) onto carbon paper disks. Increasing the content of ordered macroporous/mesoporous carbon leads to higher capacities and operating voltages. A high discharge capacity (7000 $\mathrm{mAh} \mathrm{g}^{-1}$ based on the catalyst) and operating voltage $(2.75 \mathrm{~V})$ are realized when the content of the ordered macroporous/mesoporous carbon is $50 \mathrm{wt} \%$. However, the overly high weight ratio of the ordered macroporous/ mesoporous carbon may decrease the mechanical strength of the catalytic cathode ${ }^{139}$. When the 3D ordered macroporous/mesoporous carbon is further functionalized by low-crystalline $\mathrm{Ru}$ nanoclusters, the cycle life of the related $\mathrm{Li}_{-} \mathrm{O}_{2}$ battery is greatly improved owing to the reduced side products and the undecomposed discharge products ${ }^{140}$. Generally, the ordered macroporous channels enable an effective space for $\mathrm{O}_{2}$ diffusion and $\mathrm{O}_{2} / \mathrm{Li}_{2} \mathrm{O}_{2}$ conversion, while the ordered mesoporous channels in the electrode can effectively facilitate $\mathrm{Li}$ ion diffusion and electron transfer. Although 3DOP carbon materials are commonly utilized in $\mathrm{Li}-\mathrm{O}_{2}$ batteries, one disappointing issue is that carbon-based electrocatalysts are prone to decomposition under the attack of oxygen radicals during the charging process, which may promote the degradation of electrolytes and produce the insulator $\mathrm{Li}_{2} \mathrm{CO}_{3}{ }^{141}$. The excess byproducts would block further access of $\mathrm{Li}_{2} \mathrm{O}_{2}$ to the 3DOP carbon cathode, ultimately leading to premature battery death.

To develop cheap and carbon-free electrocatalysts, $3 \mathrm{DOP} \mathrm{FePO}_{4}$ was synthesized and applied as a highefficiency catalyst for $\mathrm{Li}^{-} \mathrm{O}_{2}$ batteries ${ }^{142}$. $\mathrm{Li}-\mathrm{O}_{2}$ batteries with 3DOP $\mathrm{FePO}_{4}$ electrocatalysts exhibit a cycling life of 300 cycles with discharge voltages above $2.2 \mathrm{~V}$ at a cut-off capacity of $1000 \mathrm{mAh} \mathrm{g}^{-1}$. Because of the excellent electrochemical performance in solid oxide fuel cells, perovskite-based oxides have recently been employed as a promising electrocatalyst for $\mathrm{Li}^{-} \mathrm{O}_{2}$ batteries ${ }^{143}$. 3DOP $\mathrm{LaFeO}_{3}$ was synthesized as an electrocatalyst in an etherbased electrolyte ${ }^{144}$. The 3DOP- $\mathrm{LaFeO}_{3} /$ carbon black electrode displays a higher ORR onset potential and ORR/ OER peak current than carbon black and bulk- $\mathrm{LaFeO}_{3} /$ carbon black electrocatalysts (Fig. 9a). Using 3DOP$\mathrm{LaFeO}_{3} /$ carbon black as the cathode, the obtained charge voltage is 0.15 and $0.25 \mathrm{~V}$ lower than that of a $\mathrm{Li}-\mathrm{O}_{2}$ battery with bulk- $\mathrm{LaFeO}_{3} /$ carbon black and carbon black, respectively (Fig. 9b). Moreover, its discharge voltage is slightly higher than that of bulk- $\mathrm{LaFeO}_{3} /$ carbon black and carbon black. The unique "honeycomb" porous structure unit in 3 DOP- $\mathrm{LaFeO}_{3}$ can provide uniform $\mathrm{Li}_{2} \mathrm{O}_{2}$ and $\mathrm{Li}$ ion distribution inside the electrode due to more abundant oxygen and electrolyte transport paths.

\section{DOP electrode materials for use in supercapacitors}

In contrast to rechargeable batteries that store charge in the bulk of the electrode, supercapacitors store charge at the interface between an electrode and the electrolyte. Generally, there are two categories of supercapacitors: electric double layer capacitors (EDLCs) that store charge based on reversible electrostatic ion adsorption/desorption at the electrode/electrolyte interface and pseudocapacitors that store charge based on additional surface redox reactions as well as electrostatic absorption/desorption $^{145-149}$. 3DOP electrode materials have a continuous nanostructured skeleton with a large interfacial area, which ensures a large number of active sites for surface charge storage. 

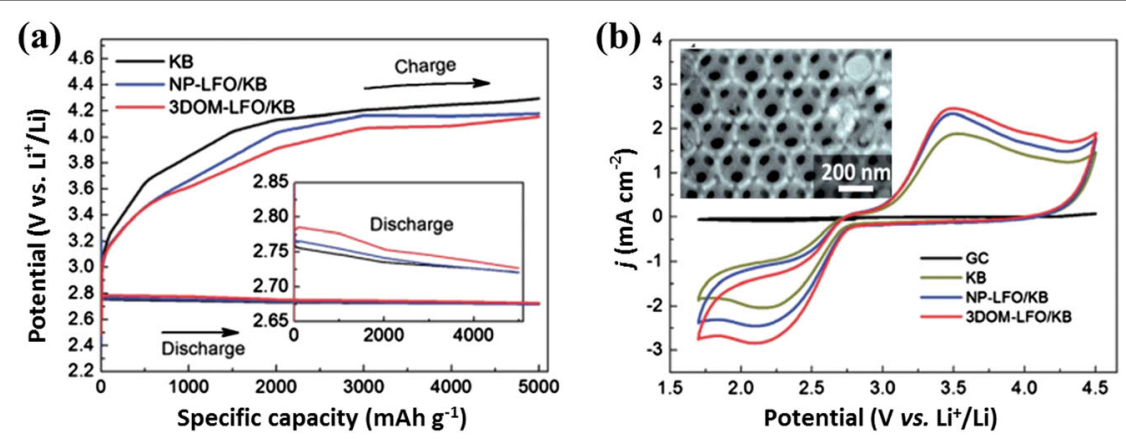

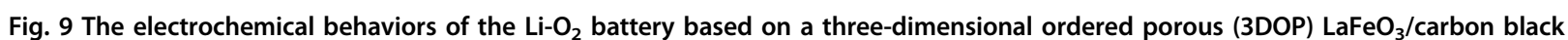
catalyst. a First charge/discharge curves of $\mathrm{Li}_{2} \mathrm{O}_{2}$ battery with carbon black (black line), nanoporous $\mathrm{LaFeO}_{3} / \mathrm{carbon}$ black (blue line), and 3DOP $\mathrm{LaFeO}_{3} /$ carbon black electrodes at a current density of $0.025 \mathrm{~mA} \mathrm{~cm}^{-2}$. b Cyclic voltammetrics of glassy carbon (black line), carbon black (yellow line), nanoporous $\mathrm{LaFeO}_{3} /$ carbon black (blue line), and $3 \mathrm{DOP} \mathrm{LaFeO}_{3} /$ carbon black (red line) recorded in an $\mathrm{O}_{2}$-saturated electrolyte at a sweep rate of $10 \mathrm{mV} \mathrm{s}^{-1}$ and a rotation rate of $900 \mathrm{rpm}$. The inset is a scanning electron microscopic image of 3DOP $\mathrm{LaFeO}_{3} / \mathrm{carbon}$ black (modified from ref. ${ }^{144}$, Copyright permission from the Royal Society of Chemistry)

\section{Electric double layer capacitors}

The electrodes for EDLCs mainly focus on carbonbased active materials with a high surface area ${ }^{2,15}$. In the case of anodes for $\mathrm{Li}$ ion batteries, the rich mesoporous structures with very high specific surface areas usually lead to low initial Coulombic efficiency due to the increased side reactions. However, this is different from EDLCs because the capacitance is proportional to the specific surface area of carbon materials to a certain degree. Thus, although 3D ordered macroporous electrode materials enable certain advantages for $\mathrm{Li}$ ion batteries, as previously discussed, one limitation of 3D ordered macroporous electrode materials is the lower surface area accessible for application in EDLCs compared to ordered mesoporous materials. Thus 3D ordered macroporous/mesoporous carbon was synthesized for EDLCs by using the colloidal crystal template method with highly ordered templates, including monodisperse $\mathrm{SiO}_{2}$ spheres, monodisperse PS latex, colloidal silica, and other opal materials ${ }^{150-153}$. These bimodal porous carbons show high capacitances of up to 120 and $130 \mathrm{~F} \mathrm{~g}^{-1}$ in $\operatorname{organic}^{150}$ and aqueous alkaline electrolytes ${ }^{151}$, respectively. Mesopores have a significant positive effect on the rate capability of the carbon electrode, and the interconnection of macropores facilitates electrolyte transport to whole surfaces. Specifically, the large number of mesopores can contribute to the adsorption of ionic species at the electrode/electrolyte interface for electric double-layer formation without an ionic sieving effect. The existence of mesopores (ranging from 2 to $50 \mathrm{~nm}$ ) greatly contributes to the total pore volume in the 3DOP carbon. Decreasing the diameter of the template spheres can greatly promote both high surface area and pore volume (Fig. 10a). The 3DOP carbon electrode with a pore size distribution of $50 \mathrm{~nm}$ shows the highest specific capacitance (Fig. 10b). The gravimetric capacitance of the
3DOP carbons increases linearly with the surface area (Fig. 10c). Although the activated carbon has a larger surface area of $1700 \mathrm{~m}^{2} \mathrm{~g}^{-1}$, its capacitance is still lower than that of the 3DOP carbon electrode with a pore size distribution of $50 \mathrm{~nm}$. In fact, micropores in carbon electrodes $<0.7 \mathrm{~nm}$ should be a disadvantage for doublelayer formation, especially in organic electrolytes, because the diameters of the $\left(\mathrm{C}_{2} \mathrm{H}_{5}\right)_{4} \mathrm{~N}^{+}$and $\mathrm{BF}_{4}{ }^{-}$ions are 0.7 and $0.5 \mathrm{~nm}$, respectively ${ }^{152}$.

The assembly of 2D graphene sheets into 3D structures is attractive for EDLCs. Free-standing foams composed of 3DOP graphene were obtained via chemical vapor deposition (CVD) grown on templated $\mathrm{Ni}$ scaffolds and etched method in concentrated $\mathrm{HCl}$ solution ${ }^{153}$. The calculated highest specific capacitance was $2.7 \mathrm{~F} \mathrm{~cm}^{-3}$ for the 3DOP graphene electrode. Unfortunately, it is difficult to synthesize a sufficient quantity of materials when using the CVD method.

\section{Pseudocapacitors}

The electrode materials of pseudocapacitors mainly include transition metal oxides, transition metal sulfides, and conductive polymer materials. A large amount of 3DOP electrode materials were demonstrated for use as pseudocapacitors in the past several years, as summarized in Table 1.

Among various transition metal oxides, $\mathrm{MnO}_{2}$ has attracted significant interest owing to its advantages of high specific capacitance, low cost, environmental friendliness, etc ${ }^{154,155}$. The electrochemical performances of 3DOP $\mathrm{MnO}_{2}$ electrodes with different pore diameters (200-900 nm) were evaluated in an aqueous $\mathrm{Na}_{2} \mathrm{SO}_{4}$ electrolyte ${ }^{156}$. It is established that the pseudocapacitive behaviors of the 3DOP $\mathrm{MnO}_{2}$ electrodes greatly depend on the electrode pore sizes. For example, the 3DOP $\mathrm{MnO}_{2}$ electrode with a pore diameter of 

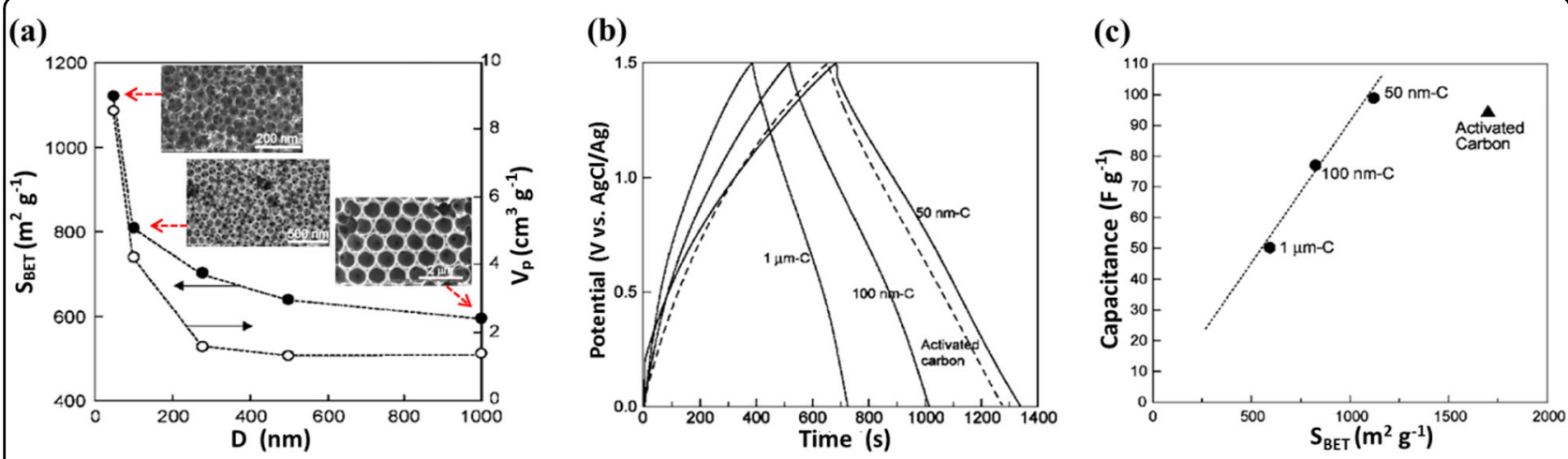

Fig. 10 The electrochemical behaviors of the three-dimensional ordered porous carbon for electric double layer capacitors. a

Brunauer-Emmett-Teller specific surface area plots and pore volume. The insets are the corresponding scanning electron microscopic images. b Typical charge and discharge curves. c The relationship between specific gravimetric capacity and specific surface area (modified from ref. ${ }^{152}$, Copyright permission from the Electrochemical Society)

Table 1 The summary of the electrochemical performance based on the 3DOP-based electrodes for pseudocapacitors

\begin{tabular}{|c|c|c|c|c|c|c|}
\hline Electrode & Ordered pores & Electrolyte & Working voltage & Specific capacitance & Cycle & Ref. \\
\hline $\mathrm{MnO}_{2}$ & $200 \mathrm{~nm}$ & $0.5 \mathrm{M} \mathrm{Na}_{2} \mathrm{SO}_{4}$ & $0-1 \vee$ & $765 \mathrm{Fg}^{-1}$ & 2000 (98\%) & 156 \\
\hline $\mathrm{MnO}_{2} \mathrm{~N}_{2} \mathrm{O}_{3}$ & $360 \mathrm{~nm}$ & $1 \mathrm{M} \mathrm{Na}_{2} \mathrm{SO}_{4}$ & $-0.8-0.8 \mathrm{~V}$ & $1301 \mathrm{Fg}^{-1}$ & $15000(86 \%)$ & 157 \\
\hline $\mathrm{MnO}_{2} / \mathrm{Mn}$ & $450 \mathrm{~nm}$ & $3 \mathrm{M} \mathrm{KCl}$ & $0-0.9 \mathrm{~V}$ & $1260 \mathrm{Fg}^{-1}$ & 2000 (96\%) & 158 \\
\hline $\mathrm{MnO}_{2} / \mathrm{C}$ & $280 \mathrm{~nm}+3.9 \mathrm{~nm}$ & $1.0 \mathrm{M} \mathrm{Na}_{2} \mathrm{SO}_{4}$ & $0-1 \vee$ & $234 \mathrm{Fg}^{-1}$ & 1000 (95\%) & 159 \\
\hline $\mathrm{MnO}_{2} / \mathrm{C}$ & $250 \mathrm{~nm}$ & $0.1 \mathrm{M} \mathrm{Na}_{2} \mathrm{SO}_{4}$ & $0-0.8 \mathrm{~V}$ & $347 \mathrm{Fg}^{-1}$ & $5500(92 \%)$ & 160 \\
\hline $\mathrm{V}_{2} \mathrm{O}_{5}$ & $165 \mathrm{~nm}$ & $1 \mathrm{M} \mathrm{LiClO}_{4} / \mathrm{PC}$ & $-1-1 \vee$ & $355 \mathrm{Fg}^{-1}$ & - & 164 \\
\hline $\mathrm{V}_{2} \mathrm{O}_{5}$ & $210 \mathrm{~nm}$ & $1 \mathrm{M} \mathrm{LiClO} / \mathrm{PC}$ & $-1-1 \vee$ & $0.05 \mathrm{Ccm}^{-2}$ & - & 167 \\
\hline $\mathrm{NiO}$ & $500 \mathrm{~nm}$ & $0.5 \mathrm{M} \mathrm{NaOH}$ & $-0.4-0.6 \mathrm{~V}$ & - & - & 171 \\
\hline $\mathrm{CO}_{3} \mathrm{O}_{4} / \mathrm{C}$ & $225 \mathrm{~nm}$ & $6 \mathrm{M} \mathrm{KOH}$ & $0-0.6 \mathrm{~V}$ & $687 \mathrm{Fg}^{-1}$ & $5000(96 \%)$ & 172 \\
\hline $\mathrm{Cu}_{2} \mathrm{O} / \mathrm{Ni}$ & $300 \mathrm{~nm}$ & $6 \mathrm{M} \mathrm{KOH}$ & $-0.2-0.4 \mathrm{~V}$ & $502 \mathrm{Fg}^{-1}$ & $500(75 \%)$ & 174 \\
\hline $\ln _{2} \mathrm{O}_{3} / \mathrm{C}$ & $250 \mathrm{~nm}$ & $6 \mathrm{M} \mathrm{KOH}$ & $0-0.5 \mathrm{~V}$ & $287 \mathrm{Fg}^{-1}$ & $5000(86 \%)$ & 175 \\
\hline$W S_{2}$ & $800 \mathrm{~nm}$ & $1 \mathrm{M} \mathrm{H}_{2} \mathrm{SO}_{4}$ & $-0.3-0.4 \mathrm{~V}$ & $262 \mathrm{Fg}^{-1}$ & $3000(95 \%)$ & 176 \\
\hline Functionalized PPy & $120 \mathrm{~nm}$ & $0.5 \mathrm{M} \mathrm{LiClO}_{4}$ & $-0.1-0.5 \mathrm{~V}$ & $130 \mathrm{~F} \mathrm{~cm}^{-3}$ & $10000(90 \%)$ & 177 \\
\hline $\mathrm{PPy} / \mathrm{CNT}$ & $500 \mathrm{~nm}$ & $1 \mathrm{M} \mathrm{KCl}$ & $-0.4-0.2 \mathrm{~V}$ & $427 \mathrm{Fg}^{-1}$ & 1000 (90\%) & 178 \\
\hline PPy/C & & $1 \mathrm{M} \mathrm{LiPF}_{6} / \mathrm{EC}-\mathrm{DEC}$ & $2-4 V$ & $140 \mathrm{Fg}^{-1}$ & - & 179 \\
\hline PANi & & $1 \mathrm{M} \mathrm{LiPF} /$ /EC-DEC & $2-4 \mathrm{~V}$ & $200 \mathrm{Fg}^{-1}$ & - & 180 \\
\hline
\end{tabular}

$C$ carbon, $C N T$ carbon nanotube, EC ethylene carbonate, DEC diethyl carbonate, 3DOP three-dimensional ordered porous, $P A N i$ polyaniline, $P C$ propylene carbonate, PPy polypyrrole

approximately $200 \mathrm{~nm}$ exhibits a specific capacitance of $390 \mathrm{~F} \mathrm{~g}^{-1}$, which is much higher than those of the 3DOP electrodes with larger pores (400 and $900 \mathrm{~nm})$. However, the low electronic conductivity $\left(10^{-5}-10^{-6} \mathrm{~S} \mathrm{~cm}^{-1}\right)$ of the $\mathrm{MnO}_{2}$ electrode results in a practical capacitance that is far lower than its theoretical capacitance $(1370 \mathrm{~F}$ $\left.\mathrm{g}^{-1}\right)$. One promising strategy to solve this problem is the incorporation of nanostructured $\mathrm{MnO}_{2}$ into a conductive metal or carbon matrix ${ }^{157}$. Thus a core-shell $\mathrm{Mn} / \mathrm{MnO}_{2}$ film was designed to anodize a 3DOP $\mathrm{Mn}$ film in a $\mathrm{KCl}$ aqueous solution, which displayed an ultrahigh specific capacitance of $1200 \mathrm{Fg}^{-1}$ at a scan rate of $10 \mathrm{mV} \mathrm{s}^{-1158}$. The core of the Mn layer greatly enhances the electron transportation for charge transfer reactions due to its large electronic conductivity. In addition to the conductive metal, the 3DOP carbon framework is a promising substrate for the $\mathrm{MnO}_{2}$ electrode $^{159,160}$, which can provide good mechanical stability and is favorable for electron transport within the well-interconnected wall structure. 
Vanadium pentoxide $\left(\mathrm{V}_{2} \mathrm{O}_{5}\right)$ is another potential electrode material for pseudocapacitors both in aqueous and organic electrolytes owing to its lamellar structure and different oxidation states ${ }^{161,162}$. In the organic electrolyte, in contrast to $\mathrm{MnO}_{2}, \mathrm{~V}_{2} \mathrm{O}_{5}$ is an extrinsic intercalation pseudocapacitive material. The intercalation pseudocapacitive behaviors of the $\mathrm{V}_{2} \mathrm{O}_{5}$ electrode become apparent only with rational engineering of its architectures at the nanoscale ${ }^{163}$. Recently, the pseudocapacitive effect of 3DOP $\mathrm{V}_{2} \mathrm{O}_{5}$ films was studied in organic Li salt electrolytes $^{164}$. The capacitive contribution of a $3 \mathrm{DOP} \mathrm{V}_{2} \mathrm{O}_{5}$ film with a pore diameter of $165 \mathrm{~nm}$ is approximately $68 \%$ at $10 \mathrm{mV} \mathrm{s}^{-1}$, which is much higher than those of films with a pore diameter of $480 \mathrm{~nm}(40 \%)$ and the compact film (18\%). The 3DOP $\mathrm{V}_{2} \mathrm{O}_{5}$ film with a wall thickness of 14 $\mathrm{nm}$ displays a capacitance-based high-rate capability and an intercalation-based high capacitance. $\mathrm{V}_{2} \mathrm{O}_{5}$ is also an excellent electrochromic oxide, which can be integrated into the electrochromic supercapacitor on the conductive transparent current collector ${ }^{165,166}$. For example, the 3DOP $\mathrm{V}_{2} \mathrm{O}_{5}$-based supercapacitor displays a higher optical contrast and faster switching response time (1.7 s for coloration and $3.2 \mathrm{~s}$ for bleaching) ${ }^{167}$. Integrating electrochromism into a supercapacitor presents a significant opportunity in the development of smart supercapacitors with imaginative and humanization features.

Nickel- or cobalt-based oxides $\left(\mathrm{NiO}\right.$ and $\left.\mathrm{Co}_{3} \mathrm{O}_{4}\right)$ show high-rate performance as electrode materials in alkaline batteries, involving typical diffusion-limited redox reactions ${ }^{168,169}$. They are often matched with EDLC-type carbon materials to fabricate hybrid supercapacitors ${ }^{170}$. $3 \mathrm{DOP} \mathrm{NiO}$ and $\mathrm{Co}_{3} \mathrm{O}_{4}$ electrodes were shown to enhance the electrochemical performance ${ }^{171,172}$. Color changes are observed during the redox process with darkening upon oxidation and bleaching upon reduction in the $3 \mathrm{DOP} \mathrm{NiO}$ electrode $^{171}$. The 3DOP $\mathrm{Co}_{3} \mathrm{O}_{4} / \mathrm{C}$ nanocomposite shows a specific capacitance of $687.5 \mathrm{~F} \mathrm{~g}^{-1}$ at $20 \mathrm{mV} \mathrm{s}^{-1}$, which is much higher than those of the 3DOP $\mathrm{Co}_{3} \mathrm{O}_{4}$ and $\mathrm{Co}_{3} \mathrm{O}_{4}$ free 3DOP carbon counterparts. Moreover, the 3DOP structure of the $\mathrm{Co}_{3} \mathrm{O}_{4} / \mathrm{C}$ nanocomposite is still well maintained after 5000 cycles $^{172}$. One disadvantage of Nior Co-based oxides is that the related charge storage generally occurs within a very narrow potential range in alkaline electrolytes. Whether their redox kinetics belong to surface-controlled pseudocapacitive behavior or diffusion-controlled battery behavior remains controversial ${ }^{173}$.

Other electrode materials with 3DOP structures, including $\mathrm{Cu}_{2} \mathrm{O}^{174}, \mathrm{In}_{2} \mathrm{O}_{3}{ }^{175}$, and $\mathrm{WS}_{2}{ }^{176}$, are also investigated for use in supercapacitors. The pseudocapacitance of the $\mathrm{Cu}_{2} \mathrm{O}$ electrode in an alkaline electrolyte originates from transitions between the oxidation states $\mathrm{Cu}(\mathrm{I})$ oxide and $\mathrm{Cu}(\mathrm{II})$ oxide and vice versa ${ }^{162}$. The surface faradaic reactions of the $\mathrm{In}_{2} \mathrm{O}_{3}$ electrode materials can be expressed as follows: the reversible transitions between the oxidation state $\left(\operatorname{In}_{2} \mathrm{O}_{3}+3 \mathrm{H}_{2} \mathrm{O}\right)$ and the reduction state $\left(\mathrm{In}+6 \mathrm{OH}^{-}\right)^{163}$. In contrast, the distinctive surface capacitive behavior of the 3D DOP $\mathrm{WS}_{2}$ electrode is associated with reversible and rapid proton insertion/ deinsertion into/out of the in-plane W-S lattice ${ }^{165}$.

Another good example of how 3DOP electrode materials facilitate good electronic and ionic conductivity can be identified in the case of organic electrodes for supercapacitors. The 3DOP organic hybrid electrode consisting of a catechol derivative and polypyrrole (PPy) was prepared by a simple one-step electrosynthesis method ${ }^{177}$. A fast redox transition of the quinone/hydroquinone pair occurs in this hybrid electrode. At a small current density of $0.4 \mathrm{~A} \mathrm{~cm}^{-3}$, this 3DOP hybrid electrode exhibits a capacitance of $130 \mathrm{~F} \mathrm{~cm}^{-3}\left(385 \mathrm{~F} \mathrm{~g}^{-1}\right)$, which is higher than those of the bulk hybrid electrode $\left(117 \mathrm{~F} \mathrm{~cm}^{-3}\right)$ and the pure PPy electrode $\left(95 \mathrm{~F} \mathrm{~cm}^{-3}\right)$. Another 3DOP PPy/ CNT composite electrode shows a specific capacitance of $427 \mathrm{~F} \mathrm{~g}^{-1}$, while the planar CNT/PPy composite film has a specific capacitance of only $128 \mathrm{Fg}^{-1178}$. A mathematical model of mass transport to evaluate the ion diffusion capability reveals that ions can approach the inside wall of the pore and then transfer much deeper into the surface of the electrode with well-ordered 3D macropores (diameter of $300 \mathrm{~nm}$ ) compared to those electrodes with a planar surface or nanosize pores (diameter of $30 \mathrm{~nm})^{178}$.

Both PPy and PANi are incorporated into the 3DOP carbon electrodes by electropolymerization of pyrrole and aniline, respectively, and the products are then examined as cathodes for supercapacitors in non-aqueous electrolytes ${ }^{179,180}$. In addition to the current response due to the formation of an electric double layer, redox current responses were observed in the $\mathrm{CV}$ curves of these 3DOP composites due to doping/undoping of $\mathrm{PF}_{6}{ }^{-}$anions into/ from PPy (or PANi). Through a combination of the redox capacity of the conductive polymers and the electric double-layer capacitance of the 3DOP carbon, large capacitances were observed for these 3DOP conducting polymer/carbon composites even at high current densities in organic electrolytes. Additionally, the incorporation of PANi and PPy into the macroporous carbon does not change the geometric volume of the carbon electrode at all, since the porosity of the 3DOP carbon is up to $70 \%$. The incorporation of PPy and PANi into the macroporous carbon electrode is an effective method to increase the volumetric energy density of 3DOP electrodes.

\section{Conclusions}

This review highlights the recent progress in the development of 3DOP electrode materials for electrochemical energy storage. In the past decade, an increasing number of 3DOP electrode materials have been exploited for use in various electrochemical energy storage devices. 
There is a strong relationship between 3DOP structures and electrochemical performance in various electrode materials. (1) Incorporating ordered porosity into anode and cathode materials for $\mathrm{Li}$ ion batteries is beneficial for fast ion and electron transport as well as robust integrity. For anode materials based on alloying and conversion reactions, volume expansion and poor electrical conductivity are serious problems that hinder the cycling stability and rate capability. On the one hand, the 3DOP structures can accommodate volume changes during lithiation and delithiation and alleviate the significant swelling and shrinkage, improving the structural stability of the electrodes. On the other hand, the high specific surface area and rich active sites of 3DOP structures very easily result in unwanted reductions and thick SEIs compared with those of their solid counterparts. (2) For electrode materials for ARLBs, the hierarchical 3D structures with well-defined pore dimensions and interconnected active sites are more effective for $\mathrm{Li}$ ion intercalation/deintercalation due to the shortened $\mathrm{Li}$ ion diffusion pathlength. Together with the high ionic conductivity of aqueous electrolytes, the ultrafast charge storage concept is demonstrated using OP cathodes in aqueous batteries. (3) In the cases of $\mathrm{Li}^{-} \mathrm{O}_{2}$ and $\mathrm{Li}-\mathrm{S}$ batteries, significant efforts have been devoted to hierarchical bimodal pore systems that contain ordered, tunable, and interconnected mesopores within the macroporous skeleton. Specifically, for the Li-S battery, the large volumetric expansion/shrinkage of sulfur during lithiation/delithiation can be almost eliminated owing to the extra free space to alleviate structural strain, thus achieving mechanical integrity and stability of the composite cathode. Of course, one key limitation of the low areal sulfur loading cannot be ignored, which may directly restrict the wide practical application of these materials. For the $\mathrm{Li}-\mathrm{O}_{2}$ battery, in addition to serving as catalysts to promote both the ORR and the OER, 3DOP cathodes will act as a substrate for the accommodation of discharge products and will facilitate the permeation of oxygen and $\mathrm{Li}$ ions with minimal diffusive resistance. There are still some other obstacles for $\mathrm{Li}-\mathrm{O}_{2}$ batteries, such as electrolytes; the unavoidable byproducts (such as $\mathrm{LiOH}$ and $\mathrm{Li}_{2} \mathrm{CO}_{3}$ ) from side reactions with the electrolyte may cover the 3DOP cathodes, thus blocking the pathways of the electrolytes and oxygen. Thus optimization of the properties and the reliability of each part of the $\mathrm{Li}-\mathrm{O}_{2}$ battery is necessary to improve the overall electrochemical performance. (4) Regarding supercapacitors, the power density is one of the most important parameters, and it determines how fast the energy can be discharged or charged. Its performance is highly dependent on the engineered pore structure. The ordered interconnected pore network of 3DOP allows easy electrolyte infiltration throughout the pores, resulting in the higher ionic conductivity and high power density of EDLCs. For pseudocapacitors, the enlarged contact between the active 3DOP materials and the electrolyte will undoubtedly contribute to outstanding surface redox charge storage.

However, there are still several challenges in this booming field. (1) Although there are great academic achievements, 3DOP materials have not yet been utilized as commercial electrodes. Some problems could be associated with their low volumetric energy/capacity values and high-cost manufacturing methods. Currently, gravimetric specific energy and capacity are the most commonly used figure-of-merit in most reported 3DOP electrode materials. However, the related volumetric values are more important parameters for practical applications, as there is always limited space for electrochemical energy devices in portable electronic products. The design of 3DOP materials usually leads to a low tap density for electrodes and, consequently, a low volumetric capacity for the electrochemical energy storage device. An efficient way to compensate for the low volumetric capacity is to deposit high-performance active materials on a 3DOP substrate. (2) For 3DOP anode materials, the formation of the SEI layer on electrodes tends to consume more electrolytes because of the larger surface areas in 3DOP anode materials than in bulk materials. Control of the specific and stable SEI on the electrode/electrolyte surface area plays a critical role in achieving the high initial Coulombic efficiency and long cycle life of electrodes ${ }^{181,182}$. (3) It is vital to further investigate new materials with OP structures, such as Mxene ${ }^{183}, 2 \mathrm{D}$ elemental materials ${ }^{184}$, and metal-organic frameworks ${ }^{185}$. It is also attractive to develop 3DOP materials with advantageous microstructures for other promising energy storage devices ${ }^{186-188}$. (4) For fundamental understanding of the charge transport properties of 3DOP materials at the nanoscale, various in situ and ex situ characterization techniques are often required to better reveal microstructural evolutions during the charge-discharge process and to fully analyze the important structure-property relationships ${ }^{189-191}$. For example, in situ stress and strain measurements of graphite-based electrodes during electrochemical cycling have been developed to calculate the electrochemical stiffness of the electrodes ${ }^{191}$. This new analytical tool and approach may offer new insights into 3DOP electrode materials. (5) The production of 3DOP electrode materials is largely demonstrated at the laboratory scale with high cost. Innovative synthesis methodologies with large-scale and low-cost production are always highly desirable ${ }^{192}$. Achieving industrial-scale production is a key next step. (6) The electrochemical behaviors of most reported 3DOP electrode materials mainly focus on the half-cell system. Obtaining highperformance full-cell devices for practical applications is still challenging because of the complex matching of the 
cathode and anode materials in terms of rate capability and volumetric capacity.

\section{Acknowledgements}

The authors gratefully acknowledge the financial support from the National Materials Genome Project (2016YFB0700600), the National Natural Science Foundation Committee of China (Distinguished Youth Scientists Project of 51425301, U1601214, 51573013, 51773092, and 51772147), the 1000 Youth Talents Plan of National Natural Science Foundation of China (51773092), the Research Foundation of State Key Lab (ZK201717), the Jiangsu Distinguished Professorship Program (2016), and the Postgraduate Research \& Practice Innovation Program of Jiangsu Province (Grant No. Kycx18_1122).

\section{Author details}

'State Key Laboratory of Materials-oriented Chemical Engineering, Nanjing Tech University, 211816 Nanjing, China. ${ }^{2}$ Institute for Advanced Materials, School of Energy Science and Engineering, Nanjing Tech University, 211816 Nanjing, Jiangsu Province, China. ${ }^{3}$ Center for Advancing Electronics Dresden (CFAED) \& Department of Chemistry and Food Chemistry, Technische Universität Dresden, 01062 Dresden, Germany

\section{Conflict of interest}

The authors declare that they have no conflict of interest.

\section{Publisher's note}

Springer Nature remains neutral with regard to jurisdictional claims in published maps and institutional affiliations.

Received: 22 June 2018 Revised: 12 September 2018 Accepted: 30 October 2018.

Published online: 14 March 2019

\section{References}

1. Li, W., Liu, J. \& Zhao, D. Mesoporous materials for energy conversion and storage devices. Nat. Rev. Mater. 1, 16023 (2016).

2. Wang, F. et al. Latest advances in supercapacitors: from new electrode materials to novel device designs. Chem. Soc. Rev. 46, 6816-6854 (2017).

3. Sun, $\boldsymbol{H}$. et al. Three-dimensional holey-graphene/niobia composite architectures for ultrahigh-rate energy storage. Science 356, 599-604 (2017).

4. Wang, C. et al. A selectively permeable membrane for enhancing cyclability of organic sodium-ion batteries. Adv. Mater. 28, 9182-9187 (2016).

5. Liu, J. et al. Mechanically and chemically robust sandwich-structured C@Si@C nanotube array Li-ion battery anodes. ACS Nano 9, 1985-1994 (2015).

6. Wang, F. et al. Nanostructured positive electrode materials for post-lithium ion batteries. Energy Environ. Sci. 9, 3570-3611 (2016).

7. Chodankar, N. R., Dubal, D. P., Kwon, Y. \& Kim, D. H. Direct growth of FeCO $\mathrm{O}_{4}$ nanowire arrays on flexible stainless steel mesh for high-performance asymmetric supercapacitor. NPG Asia Mater. 9, e419 (2017).

8. Wang, F. et al. Electrode materials with tailored facets for electrochemical energy storage. Nanoscale Horiz. 1, 272-289 (2016).

9. Bruce, P. G., Freunberger, S. A., Hardwick, L. J. \& Tarascon, J. M. Li-O 2 and Li-S batteries with high energy storage. Nat. Mater. 11, 19-29 (2012).

10. Pang, Q., Liang, X., Kwok, C. Y. \& Nazar, L. F. Advances in lithium-sulfur batteries based on multifunctional cathodes and electrolytes. Nat. Energy 1, 16132 (2016).

11. Choi, J. W. \& Aurbach, D. Promise and reality of post-lithium-ion batteries with high energy densities. Nat. Rev. Mater. 1, 16013 (2016).

12. Sun, Y., Liu, N. \& Cui, Y. Promises and challenges of nanomaterials for lithiumbased rechargeable batteries. Nat. Energy 1, 16071 (2016).

13. Wei, Q. et al. Porous one-dimensional nanomaterials: design, fabrication and applications in electrochemical energy storage. Adv. Mater. https://doi.org/ 10.1002/adma.201602300. (2017)

14. Tan, C. et al. Recent advances in ultrathin two-dimensional nanomaterials. Chem. Rev. 117, 6225-6331 (2017)

15. Peng, L., Fang, Z., Zhu, Y., Yan, C. \& Yu, G. Holey 2D nanomaterials for electrochemical energy storage. Adv. Energy Mater. https://doi.org/10.1002/ aenm.201702179 (2017).
16. Zhang, J. \& Li, C. M. Nanoporous metals: fabrication strategies and advanced electrochemical applications in catalysis, sensing and energy systems. Chem. Soc. Rev. 41, 7016-7031 (2012).

17. Wei, J. et al. New Insight into the synthesis of large-pore ordered mesoporous materials. J. Am. Chem. Soc. 139, 1706-1713 (2017).

18. Liu, S. et al. Dual-template synthesis of 2D mesoporous polypyrrole nanosheets with controlled pore size. Adv. Mater. 28, 8365-8370 (2016).

19. Liu, S. et al. Soft-template construction of 3D macroporous polypyrrole scaffolds. Small 13, 1604099 (2017).

20. Lei, Y., Yang, S., Wu, M. \& Wilde, G. Surface patterning using templates: concept, properties and device applications. Chem. Soc. Rev. 40, 1247-1258 (2011).

21. Stein, A., Wilson, B. E. \& Rudisill, S. G. Design and functionality of colloidalcrystal-templated materials-chemical applications of inverse opals. Chem. Soc. Rev. 42, 2763-2803 (2013).

22. Zhao, H., Zhou, M., Wen, L. \& Lei, Y. Template-directed construction of nanostructure arrays for highly-efficient energy storage and conversion. Nano Energy 13, 790-813 (2015).

23. Zhao, H., Liu, L., Vellacheri, R. \& Lei, Y. Recent advances in designing and fabricating self-supported nanoelectrodes for supercapacitors. Adv. Sci. 4, 1700188 (2017).

24. Stein, A., Wilson, B. E. \& Rudisill, S. G. Design and functionality of colloidalcrystal-templated materials-chemical applications of inverse opals. Chem. Soc Rev. 42, 2763-2803 (2013).

25. Zhao, Y., Liu, B., Pan, L. \& Yu, G. 3D nanostructured conductive polymer hydrogels for high-performance electrochemical devices. Energy Environ. Sci. 6, 2856-2870 (2013).

26. $\mathrm{Xu}$, J. et al. $\mathrm{G}$. Three-dimensional structural engineering for energy-storage devices: from microscope to macroscope. ChemElectroChem 1, 975-1002 (2014).

27. Rolison, D. R. \& Dunn, B. Electrically conductive oxide aerogels: new materials in electrochemistry. J. Mater. Chem. 11, 963-980 (2001).

28. Long, J. W., Dunn, B., Rolison, D. R. \& White, H. S. Three-dimensional battery architectures. Chem. Rev. 104, 4463-4492 (2004).

29. Long, J. W. \& Rolison, D. R. Architectural design, interior decoration, and three-dimensional plumbing en route to multifunctional nanoarchitectures. Acc. Chem. Res. 40, 854-862 (2007).

30. Wu, F., Bai, J., Feng, J. \& Xiong, S. Porous mixed metal oxides: design, formation mechanism, and application in lithium-ion batteries. Nanoscale $\mathbf{7}$, 17211-17230 (2015).

31. Fu, L. J. et al. Synthesis and electrochemical performance of novel core/shell structured nanocomposites. Electrochem. Commun. 8, 1-4 (2006).

32. Wang, $\mathrm{C}$. et al. Hollow $\mathrm{TiO}_{2-x}$ porous microspheres composed of wellcrystalline nanocrystals for high-performance lithium-ion batteries. Nano Res. 9, 165-173 (2016).

33. Wang, F. et al. A quasi-solid-state Li-ion capacitor based on porous $\mathrm{TiO}_{2}$ hollow microspheres wrapped with graphene nanosheets. Small 12, 6207-6213 (2016).

34. Fu, L., Zhang, T., Cao, Q., Zhang, H. P. \& Wu, Y. P. Preparation and characterization of three-dimensionally ordered mesoporous titania microparticles as anode material for lithium ion battery. Electrochem. Commun. $\mathbf{9}$ 2140-2144 (2007)

35. Lui, G. et al. Flexible, three-dimensional ordered macroporous $\mathrm{TiO}_{2}$ electrode with enhanced electrode-electrolyte interaction in high-power Li-ion batteries. Nano Energy 24, 72-77 (2016).

36. McNulty, D., Carroll, E. \& O'Dwyer, C. Rutile TiO, inverse opal anodes for Liion batteries with long cycle life, high-rate capability, and high structural stability. Adv. Energy Mater. https:/doi.org/10.1002/aenm.201602291 (2017).

37. Petkovich, N. D., Rudisill, S. G., Wilson, B. E., Mukherjee, A. \& Stein, A. Control of $\mathrm{TiO}_{2}$ grain size and positioning in three-dimensionally ordered macroporous $\mathrm{TiO}_{2} / \mathrm{C}$ composite anodes for lithium ion batteries. Inorg. Chem. 53, 1100-1112 (2014)

38. Song, L. et al. A facile synthesis of a uniform constitution of threedimensionally ordered macroporous $\mathrm{TiO}_{2}$-carbon nanocomposites with hierarchical pores for lithium ion batteries. J. Mater. Chem. A 3, 6862-6872 (2015).

39. Wang, $\mathrm{X}$. et al. Synthesis and lithium storage properties of $\mathrm{CO}_{3} \mathrm{O}_{4}$ nanosheetassembled multishelled hollow spheres. Adv. Funct. Mater. 20, 1680-1686 (2010). 
40. Peng, $\mathrm{C}$. et al. Facile ultrasonic synthesis of $\mathrm{CoO}$ quantum dot/graphene nanosheet composites with high lithium storage capacity. ACS Nano $\mathbf{6}$, 1074-1081 (2012).

41. Wang, J. et al. Accurate control of multishelled $\mathrm{CO}_{3} \mathrm{O}_{4}$ hollow microspheres as high-performance anode materials in lithium-ion batteries. Angew. Chem. Int. Ed. 52, 6417-6420 (2013).

42. Huang, $X$. et al. Carbon inverse opal entrapped with electrode active nanoparticles as high-performance anode for lithium-ion batteries. Sci. Rep. $\mathbf{3}$, 2317-2325 (2013).

43. Liu, J. et al. Hydrothermal fabrication of three-dimensional secondary battery anodes. Adv. Mater. 26, 7096-7101 (2014).

44. Liu, J. et al. Three-dimensionally scaffolded $\mathrm{CO}_{3} \mathrm{O}_{4}$ nanosheet anodes with high rate performance. J. Power Sources 299, 40-48 (2015).

45. Reddy, M. V., Pecquenard, B., Vinatier, P. \& Levasseur, A. Cyclic voltammetry and galvanostatic cycling characteristics of $\mathrm{LiNiVO}_{4}$ thin films during lithium insertion and re/de-insertion. Electrochem. Commun. 9, 409-415 (2007).

46. Liu, Z., Mi, J., Yang, Y., Li, J. \& Tan, X. Synthesis, characterization and electrochemical properties of three-dimensionally ordered macroporous $\mathrm{a}-\mathrm{Fe}_{2} \mathrm{O}_{3}$. Mater. Sci. Eng. B 177, 1612-1617 (2012).

47. Liu, $\mathrm{H}$. et al. Electrochemical performance of $\mathrm{a}-\mathrm{Fe}_{2} \mathrm{O}_{3}$ nanorods as anode material for lithium-ion cells. Electrochim. Acta 54, 1733-1736 (2009).

48. Reddy, M. V. et al. a- $\mathrm{Fe}_{2} \mathrm{O}_{3}$ nanoflakes as an anode material for Li-ion batteries. Adv. Funct. Mater. 17, 2792-2799 (2007).

49. Wang, J., Zhou, H., Nanda, J. \& Braun, P. V. Three-dimensionally mesostructured $\mathrm{Fe}_{2} \mathrm{O}_{3}$ electrodes with good rate performance and reduced voltage hysteresis. Chem. Mater. 27, 2803-2811 (2015).

50. Wang, Z., Luan, D., Madhavi, S., Hu, Y. \& Lou, X. W. D. Assembling carboncoated $\mathrm{a}-\mathrm{Fe}_{2} \mathrm{O}_{3}$ hollow nanohorns on the CNT backbone for superior lithium storage capability. Energy Environ. Sci. 5, 5252-5256 (2012).

51. Liu, J. et al. High full-electrode basis capacity template-free 3D nanocomposite secondary battery anodes. Small 11, 6265-6271 (2015).

52. Tang, Y. et al. An internal magnetic field strategy to reuse pulverized active materials for high performance: a magnetic three-dimensional ordered macroporous $\mathrm{TiO}_{2} / \mathrm{CoPt} / \mathrm{a}-\mathrm{Fe}_{2} \mathrm{O}_{3}$ nanocomposite anode. Chem. Commun. 53, 5298-5301 (2017).

53. Zhao, $\mathrm{N}$. et al. Preparation of nanowire arrays of amorphous carbon nanotube-coated single crystal $\mathrm{SnO}_{2}$. Chem. Mater. 20, 2612-2614 (2008).

54. Zhao, N. H. et al. Polycrystalline $\mathrm{SnO}_{2}$ nanowires coated with amorphous carbon nanotube as anode material for lithium ion batteries. Mater. Lett. 64 972-975 (2010).

55. Huang, J. Y. et al. In-situ observation of the electrochemical lithiation of a single $\mathrm{SnO}_{2}$ nanowire electrode. Science 330, 1515-1520 (2010).

56. Lytle, J. C., Yan, H., Ergang, N. S., Smyrl, W. H. \& Stein, A. Structural and electrochemical properties of three-dimensionally ordered macroporous tin (IV) oxide films. J. Mater. Chem. 14, 1616-1622 (2004).

57. Li, Z. et al. Three-dimensionally ordered macroporous $\mathrm{SnO}_{2}$ as anode materials for lithium ion batteries. Ceram. Int. 42, 18887-18893 (2016).

58. Liu, J. et al. High volumetric capacity three-dimensionally sphere-caged secondary battery anodes. Nano Lett. 16, 4501-4507 (2016).

59. Yuan, Y., Amine, K., Lu, J. \& Shahbazian-Yassar, R. Understanding materials challenges for rechargeable ion batteries with in situ transmission electron microscopy. Nat. Commun. 8, 15806 (2017).

60. Zhang, T. et al. Natural graphite coated by Si nanoparticles as anode materials for lithium ion batteries. J. Mater. Chem. 17, 1321-1325 (2007).

61. Zhang, T. et al. Core-shell Si/C nanocomposite as anode material for lithium ion batteries. Pure Appl. Chem. 78, 1889-1896 (2006).

62. Zhang, T. et al. The structural evolution and lithiation behavior of vacuumdeposited Si film with high reversible capacity. Electrochim. Acta 53, 5660-5664 (2008).

63. Park, M. H. et al. Silicon nanotube battery anodes. Nano Lett. 9, 3844-3847 (2009).

64. Liu, H., Cho, H. M., Meng, Y. S. \& Li, Q. Engineering three-dimensionally electrodeposited Si-on-Ni inverse opal structure for high volumetric capacity Li-ion microbattery anode. ACS Appl. Mater. Interfaces 6, 9842-9849 (2014).

65. Kim, D. Y. et al. An electrochemically grown three-dimensional porous Si@Ni inverse opal structure for high-performance Li ion battery anodes. J. Mater. Chem. A 2, 6396-6401 (2014).

66. Jin, Y., Munakata, H., Okada, N. \& Kanamura, K. Design and evaluation of a three dimensionally ordered macroporous structure within a highly patterned cylindrical $\mathrm{Sn}-\mathrm{Ni}$ electrode for advanced lithium ion batteries. J. Nanomater. https://doi.org/10.1155/2013/937019 (2013).
67. Cho, H. H., Glazer, M. P., Xu, Q., Han, H. N. \& Dunand, D. C. Numerical and experimental investigation of (de) lithiation-induced strains in bicontinuous silicon-coated nickel inverse opal anodes. Acta Mater. 107, 289-297 (2016).

68. Glazer, M. P. et al. In operando strain measurement of bicontinuous siliconcoated nickel inverse opal anodes for Li-ion batteries. Adv. Energy Mater. $\mathbf{5}$, 1500466 (2015).

69. Wang, Z. L., Xu, D., Wang, H. G., Wu, Z. \& Zhang, X. B. In-situ fabrication of porous graphene electrodes for high-performance energy storage. ACS Nano 7, 2422-2430 (2013)

70. Lou, $\mathrm{S}$. et al. Superior performance of ordered macroporous $\mathrm{TiNb}_{2} \mathrm{O}_{7}$ anodes for lithium ion batteries: Understanding from the structural and pseudocapacitive insights on achieving high rate capability. Nano Energy 34, 15-25 (2017).

71. Deng, Z. et al. 3D ordered macroporous $\mathrm{MoS}_{2} @ \mathrm{C}$ nanostructure for flexible Li-ion batteries. Adv. Mater. https://doi.org/10.1002/adma.201603020 (2017).

72. Liu, X., Zhao, J., Hao, J., Su, B. L. \& Li, Y. 3D ordered macroporous germanium fabricated by electrodeposition from an ionic liquid and its lithium storage properties. J. Mater. Chem. A 1, 15076-15081 (2013).

73. Song, T. et al. A Ge inverse opal with porous walls as an anode for lithium ion batteries. Energy Environ. Sci. 5, 9028-9033 (2012).

74. McNulty, D., Geaney, H., Buckley, D. \& O'Dwyer, C. High capacity binder-free nanocrystalline $\mathrm{GeO}_{2}$ inverse opal anodes for Li-ion batteries with long cycle life and stable cell voltage. Nano Energy 43, 11-21 (2018).

75. Wang, J. et al. Graphene microsheets from natural microcrystalline graphite minerals: scalable synthesis and unusual energy storage. J. Mater. Chem. A $\mathbf{3}$ 3144-3150 (2015).

76. Augustyn, $\mathrm{V}$. et al. High-rate electrochemical energy storage through $\mathrm{Li}^{+}$ intercalation pseudocapacitance. Nat. Mater. 12, 518-522 (2013).

77. Brezesinski, T., Wang, J., Tolbert, S. H. \& Dunn, B. Ordered mesoporous a$\mathrm{MoO}_{3}$ with iso-oriented nanocrystalline walls for thin-film pseudocapacitors. Nat. Mater. 9, 146-151 (2010).

78. Kim, H. S. et al. Oxygen vacancies enhance pseudocapacitive charge storage properties of $\mathrm{MoO}_{3-x}$. Nat. Mater. 16, 454-460 (2017).

79. Zhou, F., Xin, S., Liang, H. W., Song, L. T. \& Yu, S. H. Carbon nanofibers decorated with molybdenum disulfide nanosheets: synergistic lithium storage and enhanced electrochemical performance. Angew. Chem. Int. Ed. 53, 11552-11556 (2014).

80. Yu, X. Y., Hu, H., Wang, Y., Chen, H. \& Lou, X. W. Ultrathin MoS 2 nanosheets supported on $\mathrm{N}$-doped carbon nanoboxes with enhanced lithium storage and electrocatalytic properties. Angew. Chem. Int. Ed. 54, 7395-7398 (2015).

81. Pratt, B. \& Friedman, F. Diffusion of lithium into Ge and Si. J. Appl. Phys. 37, 1893 (1966).

82. Wang, X., Qu, Q., Hou, Y., Wang, F. \& Wu, Y. An aqueous rechargeable lithium battery of high energy density based on coated Li metal and $\mathrm{LiCOO}_{2}$. Chem. Commun. 49, 6179-6181 (2013).

83. $\mathrm{Fu}, \mathrm{L}$. J. et al. Q. Electrode materials for lithium secondary batteries prepared by sol-gel methods. Prog. Mater. Sci. 50, 881-928 (2005).

84. Cao, Q. et al. A novel carbon-coated $\mathrm{LiCOO}_{2}$ as cathode material for lithium ion battery. Electrochem. Commun. 9, 1228-1232 (2007).

85. Shi, Y. et al. Graphene wrapped LiFePO $/$ /C composites as cathode materials for Li-ion batteries with enhanced rate capability. J. Mater. Chem. 22 16465-16470 (2012).

86. Xiao, S., Wang, F., Yang, Y., Chang, Z. \& Wu, Y. An environmentally friendly and economic membrane based on cellulose as a gel polymer electrolyte for lithium ion batteries. RSC Adv. 4, 76-81 (2014).

87. $\mathrm{Liu}, \mathrm{H}$. et al. Kinetic study on $\mathrm{LiFePO}_{4} / \mathrm{C}$ nanocomposites synthesized by solid state technique. J. Power Sources 159, 717-720 (2006).

88. Ergang, N. S., Lytle, J. C., Yan, H. \& Stein, A. Effect of a macropore structure on cycling rates of $\mathrm{LiCOO}_{2}$. J. Electrochem. Soc. 152, A1989-A1995 (2005).

89. Peng, J. et al. Synthesis and electrochemical performance of threedimensionally ordered macroporous $\mathrm{LiCoO}_{2}$. J. Solid State Electrochem. 16, 3079-3085 (2012).

90. Vu, A. \& Stein, A. Multiconstituent synthesis of $\mathrm{LiFePO}_{4} / \mathrm{C}$ composites with hierarchical porosity as cathode materials for lithium ion batteries. Chem. Mater. 23, 3237-3245 (2011).

91. Doherty, C. M., Caruso, R. A., Smarsly, B. M. \& Drummond, C. J. Colloidal crystal templating to produce hierarchically porous $\mathrm{LiFePO}_{4}$ electrode materials for high power lithium ion batteries. Chem. Mater. 21, 2895-2903 (2009).

92. Kong, F. et al. Ab initio study of doping effects on $\mathrm{LiMnO}_{2}$ and $\mathrm{Li}_{2} \mathrm{MnO}_{3}$ cathode materials for Li-ion batteries. J. Mater. Chem. A 3, 8489-8500 (2015). 
93. Ji, H., Miao, X., Wang, L., Qian, B. \& Yang, G. Effects of microwavehydrothermal conditions on the purity and electrochemical performance of orthorhombic $\mathrm{LiMnO}_{2}$. ACS Sustain. Chem. Eng. 2, 359-366 (2014).

94. Guo, J., Cai, Y., Zhang, S., Chen, S. \& Zhang, F. Core-shell structured o$\mathrm{LiMnO}_{2} @ \mathrm{Li}_{2} \mathrm{CO}_{3}$ nanosheet array cathode for high-performance, widetemperature-tolerance lithium-ion batteries. ACS Appl. Mater. Interfaces 8 , 16116-16124 (2016).

95. Zhang, H., Yu, X. \& Braun, P. V. Three-dimensional bicontinuous ultrafastcharge and-discharge bulk battery electrodes. Nat. Nanotech. 6, 277-281 (2011).

96. Pikul, J. H., Zhang, H. G., Cho, J., Braun, P. V. \& King, W. P. High-power lithium ion microbatteries from interdigitated three-dimensional bicontinuous nanoporous electrodes. Nat. Commun. 4, 1732-1736 (2013).

97. Ning, $H$. et al. Holographic patterning of high-performance on-chip 3D lithium-ion microbatteries. Proc. Natl Acad. Sci. USA 112, 6573-6578 (2015).

98. Wang, F. et al. Dual-graphene rechargeable sodium battery. Small 13, 1702449 (2017).

99. Yang, J. et al. Tuning structural stability and lithium-storage properties by $\mathrm{d}$ orbital hybridization substitution in full tetrahedron $\mathrm{Li}_{2} \mathrm{FeSiO}_{4}$ nanocrystal. Nano Energy 20, 117-125 (2016).

100. Chakrabarti, S., Thakur, A. K. \& Biswas, K. Effect of Ti modification on structural, electronic and electrochemical properties of $\mathrm{Li}_{2} \mathrm{FeSiO}_{4}-\mathrm{A}$ DFT study using FPLAPW approach. Electrochim. Acta 236, 288-296 (2017).

101. Wang, W. et al. Carbon nanotube directed three-dimensional porous $\mathrm{Li}_{2} \mathrm{Fe}-$ $\mathrm{SiO}_{4}$ composite for lithium batteries. Nano Res. 10, 229-237 (2017).

102. Ding, Z. et al. Three-dimensionally ordered macroporous $\mathrm{Li}_{2} \mathrm{FeSiO}_{4} / \mathrm{C}$ composite as a high performance cathode for advanced lithium ion batteries. J. Power Sources 329, 297-304 (2016).

103. Li, D. et al. Soft-template construction of three-dimensionally ordered inverse opal structure from $\mathrm{Li}_{2} \mathrm{FeSiO}_{4} / \mathrm{C}$ composite nanofibers for high-rate lithiumion batteries. Nanoscale 8, 12202-12214 (2016).

104. Liang, S. et al. Carbon wrapped hierarchical $\mathrm{Li}_{3} \mathrm{~V}_{2}\left(\mathrm{PO}_{4}\right)_{3}$ microspheres for high performance lithium ion batteries. Sci. Rep. 6, 33682-33689 (2016).

105. Nan, $X$. et al. Highly efficient storage of pulse energy produced by triboelectric nanogenerator in $\mathrm{Li}_{3} \mathrm{~V}_{2}\left(\mathrm{PO}_{4}\right)_{3} / \mathrm{C}$ cathode Li-ion batteries. ACS Appl. Mater. Interfaces 8, 862-870 (2016).

106. Li, D. et al. Three-dimensionally ordered macroporous $\mathrm{Li}_{3} \mathrm{~V}_{2}\left(\mathrm{PO}_{4}\right)_{3} / \mathrm{C}$ nanocomposite cathode material for high-capacity and high-rate Li-ion batteries. Nanoscale 6, 3302-3308 (2014).

107. Wang, S., Zhang, Z., Deb, A., Yang, L. \& Hirano, S. I. Synthesis, characterization, and electrochemical performance of Ce-doped ordered macroporous $\mathrm{Li}_{3} \mathrm{~V}_{2}\left(\mathrm{PO}_{4}\right)_{3} / \mathrm{C}$ cathode materials for lithium ion batteries. Ind. Eng. Chem. Res. 53, 19525-19532 (2014).

108. Armstrong, E., McNulty, D., Geaney, H. \& O'Dwyer, C. Electrodeposited structurally stable $\mathrm{V}_{2} \mathrm{O}_{5}$ inverse opal networks as high performance thin film lithium batteries. ACS Appl. Mater. Interfaces 7, 27006-27015 (2015).

109. Liu, J. et al. Graphene sandwiched mesostructured Li-ion battery electrodes. Adv. Mater. 28, 7696-7702 (2016).

110. Liu, C. et al. An all-in-one nanopore battery array. Nat. Nanotech 9, 1031-1039 (2014).

111. Gillette, E. I., Kim, N., Rubloff, G. W. \& Lee, S. B. Interconnected mesoporous $\mathrm{V}_{2} \mathrm{O}_{5}$ electrode: impact on lithium ion insertion rate. Phys. Chem. Chem. Phys. 18, 30605-30611 (2016).

112. Liu, C., Kim, N., Rubloff, G. W. \& Lee, S. B. High performance asymmetric $\mathrm{V}_{2} \mathrm{O}_{5}-\mathrm{SnO}_{2}$ nanopore battery by atomic layer deposition. Nanoscale $\mathbf{9}$ 11566-11573 (2017).

113. Li, L., Zhu, J., Xu, M., Jiang, J. \& Li, C. M. In-situ engineering toward core regions: a smart way to make applicable FeF $F_{3} @$ carbon nanoreactor cathodes for Li-ion batteries. ACS Appl. Mater. Interfaces 9, 17992-18000 (2017).

114. Ma, D. L. et al. Three-dimensionally ordered macroporous $\mathrm{FeF}_{3}$ and its in-situ homogenous polymerization coating for high energy and power density lithium ion batteries. Energy Environ. Sci. 5, 8538-8542 (2012).

115. Qu, Q. et al. Porous $\mathrm{LiMn}_{2} \mathrm{O}_{4}$ as cathode material with high power and excellent cycling for aqueous rechargeable lithium batteries. Energy Environ. Sci. 4, 3985-3990 (2011).

116. Zheng, J. et al. Janus solid-liquid interface enabling ultrahigh charging and discharging rate for advanced lithium-ion batteries. Nano Lett. 15, 6102-6109 (2015).

117. Hou, Y. et al. Macroporous $\mathrm{LiFePO}_{4}$ as a cathode for an aqueous rechargeable lithium battery of high energy density. J. Mater. Chem. A 1, 14713-14718 (2013).
118. $\mathrm{Xu}, \mathrm{R} ., \mathrm{Lu}, \mathrm{J}$. \& Amine, K. Progress in mechanistic understanding and characterization techniques of Li-S batteries. Adv. Energy Mater. 5, 1500408 (2015).

119. Pang, Q., Liang, X., Kwok, C. Y., Kulisch, J. \& Nazar, L. F. A comprehensive approach toward stable lithium-sulfur batteries with high volumetric energy density. Adv. Energy Mater. 7, 1601630 (2017).

120. Xiong, P., Zhu, J., Zhang, L. \& Wang, X. Recent advances in graphene-based hybrid nanostructures for electrochemical energy storage. Nanoscale Horiz. 1, 340-374 (2016).

121. Xu, Z. L., Kim, J. K. \& Kang, K. Carbon nanomaterials for advanced lithium sulfur batteries. Nano Today https://doi.org/10.1016/j.nantod.2018.02.006 (2018).

122. Evers, S. \& Nazar, L. F. New approaches for high energy density lithium-sulfur battery cathodes. Acc. Chem. Res. 46, 1135-1143 (2012).

123. Schuster, J. et al. Spherical ordered mesoporous carbon nanoparticles with high porosity for lithium-sulfur batteries. Angew. Chem. 124, 3651-3655 (2012).

124. Wang, H., Huang, K., Wang, P. \& Zhong, J. Synthesizing nitrogen-doped porous carbon@ sulfur cathode for high-performance and stable cycling Li-S batteries. J. Alloy Comp. 691, 613-618 (2017).

125. Hu, C. et al. A high-volumetric-capacity cathode based on interconnected close-Packed N-doped porous carbon nanospheres for long-life lithium-sulfur batteries. Adv. Energy Mater. https://doi.org/10.1002/aenm.201701082 (2017).

126. Liu, S. et al. Superhierarchical cobalt-embedded nitrogen-doped porous carbon nanosheets as two-in-one hosts for high-performance lithium-sulfur batteries. Adv. Mater. 30, 1706895 (2018).

127. Zhou, Y. et al. Enabling prominent high-rate and cycle performances in one lithium-sulfur battery: designing permselective gateways for $\mathrm{Li}^{+}$transportation in holey-CNT/S cathodes. Adv. Mater. 27, 3774-3781 (2015).

128. Chang, N., Zhou, C., Fu, H., Zhao, Y. \& Shui, J. One-pot synthesis of functionalized holey graphene/sulfur composite for lithium-sulfur batteries. Adv Mater. Interfaces 4, 1700783 (2017).

129. Tachikawa, N. et al. Reversibility of electrochemical reactions of sulfur supported on inverse opal carbon in glyme-Li salt molten complex electrolytes. Chem. Commun. 47, 8157-8159 (2011).

130. Zhang, S. et al. Optimization of pore structure of cathodic carbon supports for solvate ionic liquid electrolytes based lithium-sulfur batteries. ACS Appl. Mater. Interfaces 8, 27803-27813 (2016).

131. Evers, S. \& Nazar, L. F. New approaches for high energy density lithium-sulfur battery cathodes. Acc. Chem. Res. 46, 1135-1143 (2012)

132. Peng, Z., Freunberger, S. A., Chen, Y. \& Bruce, P. G. A reversible and higherrate $\mathrm{Li}_{-} \mathrm{O}_{2}$ battery. Science 337, 563-566 (2012).

133. Li, F., Zhang, T. \& Zhou, H. Challenges of non-aqueous Li-O batteries: electrolytes, catalysts, and anodes. Energy Environ. Sci. 6, 1125-1141 (2013).

134. Liu, $\mathrm{L}$. et al. $3 \mathrm{D}$ hierarchical porous $\mathrm{CO}_{3} \mathrm{O}_{4}$ nanotube network as efficient cathode for rechargeable lithium-oxygen batteries. J. Mater. Chem. A 5, 14673-14681 (2017)

135. Zhang, T. \& Zhou, H. A reversible long-life lithium-air battery in ambient air Nat. Commun. 4, 1817-1823 (2013).

136. Liu, L. et al. Self-assembled 3D foam-like $\mathrm{NiCO}_{2} \mathrm{O}_{4}$ as efficient catalyst for lithium oxygen batteries. Small 12, 602-611 (2016).

137. Torayev, A. et al. Stochasticity of pores interconnectivity in $\mathrm{Li}^{-} \mathrm{O}_{2}$ batteries and its impact on the variations in electrochemical performance. J. Phys. Chem. Lett. 9, 791-797 (2018).

138. Kim, J. H., Oh, Y. J. \& Kang, Y. C. Design and synthesis of macroporous ( $\mathrm{Mn}_{1}$ $\left.{ }_{3} \mathrm{CO}_{2 / 3}\right) \mathrm{O}$-carbon nanotubes composite microspheres as efficient catalysts for rechargeable $\mathrm{Li}_{-} \mathrm{O}_{2}$ batteries. Carbon 128, 125-133 (2018).

139. Guo, Z. et al. Ordered hierarchical mesoporous/macroporous carbon: a highperformance catalyst for rechargeable $\mathrm{Li}_{-} \mathrm{O}_{2}$ batteries. Adv. Mater. 25 5668-5672 (2013)

140. Yang, W. et al. Hierarchical ordered macroporous/ultrathin mesoporous carbon architecture: a promising cathode scaffold with excellent rate performance for rechargeable $\mathrm{Li}_{2} \mathrm{O}_{2}$ batteries. Carbon 118, 139-147 (2017).

141. Wang, K. X., Zhu, Q. C. \& Chen, J. S. Strategies toward high-performance cathode materials for lithium-oxygen batteries. Small 14, 1800078 (2018).

142. Li, C. et al. Three-dimensional ordered macroporous $\mathrm{FePO}_{4}$ as high-efficiency catalyst for rechargeable $\mathrm{Li}_{-} \mathrm{O}_{2}$ batteries. ACS Appl. Mater. Interfaces 8 31638-31645 (2016). 
143. Zhao, Y. et al. Hierarchical mesoporous perovskite $\mathrm{La}_{0.5} \mathrm{Sr}_{0.5} \mathrm{CoO}_{2.91}$ nanowires with ultrahigh capacity for Li-air batteries. Proc. Natl. Acad. Sci. USA 109 19569-19574 (2012).

144. Xu, J. J., Wang, Z. L., Xu, D., Meng, F. Z. \& Zhang, X. B. 3D ordered macroporous $\mathrm{LaFeO}_{3}$ as efficient electrocatalyst for $\mathrm{Li}-\mathrm{O}_{2}$ batteries with enhanced rate capability and cyclic performance. Energy Environ. Sci. 7, 2213-2219 (2014)

145. Salanne, M. et al. Efficient storage mechanisms for building better supercapacitors. Nat. Energy 1, 16070 (2016).

146. Jeżowski, P. et al. Safe and recyclable lithium-ion capacitors using sacrificial organic lithium salt. Nat. Mater. https://doi.org/10.1038/nmat5029 (2017).

147. Wang, F. et al. Electrode materials for aqueous asymmetric supercapacitors. RSC Adv. 3, 13059-13084 (2013).

148. Wang, F. et al. Nanoporous $\mathrm{LiMn}_{2} \mathrm{O}_{4}$ spinel prepared at low temperature as cathode material for aqueous supercapacitors. J. Power Sources 242, 560-565 (2013)

149. Yu, F., Zhu, L., You, T., Wang, F. \& Wen, Z. Preparation of chestnut-like porous $\mathrm{NiO}$ nanospheres as electrodes for supercapacitors. RSC Adv. 5, 96165-96169 (2015).

150. Woo, S. W., Dokko, K., Nakano, H. \& Kanamura, K. Preparation of three dimensionally ordered macroporous carbon with mesoporous walls for electric double-layer capacitors. J. Mater. Chem. 18, 1674-1680 (2008).

151. Zhao, Y. et al. Easy synthesis of ordered meso/macroporous carbon monolith for use as electrode in electrochemical capacitors. Mater. Lett. 62, 548-551 (2007)

152. Tabata, S., Isshiki, Y. \& Watanabe, M. Inverse opal carbons derived from a polymer precursor as electrode materials for electric double-layer capacitors. J. Electrochem. Soc. 155, K42-K49 (2008).

153. Hsia, B. et al. Templated 3D ultrathin CVD graphite networks with controllable geometry: synthesis and application as supercapacitor electrodes. ACS Appl. Mater. Interfaces 6, 18413-18417 (2014).

154. Qu, Q. et al. Electrochemical performance of $\mathrm{MnO}_{2}$ nanorods in neutral aqueous electrolytes as a cathode for asymmetric supercapacitors. J. Phys. Chem. C. 113, 14020-14027 (2009).

155. Tang, W. et al. A hybrid of $\mathrm{MnO}_{2}$ nanowires and MWCNTs as cathode of excellent rate capability for supercapacitors. J. Power Sources 197, 330-333 (2012).

156. Sawangphruk, M. \& Limtrakul, J. Effects of pore diameters on the pseudocapacitive property of three-dimensionally ordered macroporous manganese oxide electrodes. Mater. Lett. 68, 230-233 (2012).

157. Lang, X. Y. et al. Ultrahigh-power pseudocapacitors based on ordered porous heterostructures of electron-correlated oxides. Adv. Sci. 3, https://doi.org/ 10.1002/advs.201500319 (2016).

158. Deng, M. J. et al. Fabrication of $\mathrm{Mn} / \mathrm{Mn}$ oxide core-shell electrodes with three-dimensionally ordered macroporous structures for high-capacitance supercapacitors. Energy Environ. Sci. 6, 2178-2185 (2013).

159. Yang, C., Zhou, M. \& Xu, Q. Three-dimensional ordered macroporous $\mathrm{MnO}_{2} /$ carbon nanocomposites as high-performance electrodes for asymmetric supercapacitors. Phys. Chem. Chem. Phys. 15, 19730-19740 (2013).

160. Liu, Z., Tan, X., Gao, X. \& Song, L. Synthesis of three-dimensionally ordered macroporous manganese dioxide-carbon nanocomposites for supercapacitors. J. Power Sources 267, 812-820 (2014).

161. Qu, Q., Zhu, Y., Gao, X. \& Wu, Y. Core-shell structure of polypyrrole grown on $\mathrm{V}_{2} \mathrm{O}_{5}$ nanoribbon as high performance anode material for supercapacitors. Adv. Energy Mater. 2, 950-955 (2012).

162. $\mathrm{Qu}, \mathrm{Q}$. T. et al. $\mathrm{V}_{2} \mathrm{O}_{5} \cdot 0.6 \mathrm{H}_{2} \mathrm{O}$ nanoribbons as cathode material for asymmetric supercapacitor in $\mathrm{K}_{2} \mathrm{SO}_{4}$ solution. Electrochem. Commun. 11, 1325-1328 (2009)

163. Augustyn, V., Simon, P. \& Dunn, B. Pseudocapacitive oxide materials for highrate electrochemical energy storage. Energy Environ. Sci. 7, 1597-1614 (2014).

164. Tong, Z., Xu, H., Liu, G., Zhao, J. \& Li, Y. Pseudocapacitive effect and Li ${ }^{+}$ diffusion coefficient in three-dimensionally ordered macroporous vanadium oxide for energy storage. Electrochem. Commun. 69, 46-49 (2016).

165. Zhang, P. et al. Stimulus-responsive micro-supercapacitors with ultrahigh energy density and reversible electrochromic window. Adv. Mater. 29, https://doi.org/10.1002/adma.201604491 (2017).

166. Wei, D. et al. A nanostructured electrochromic supercapacitor. Nano Lett. 12, 1857-1862 (2012).

167. Tong, Z. et al. Improved electrochromic performance and lithium diffusion coefficient in three-dimensionally ordered macroporous $\mathrm{V}_{2} \mathrm{O}_{5}$ films. J. Mater. Chem. C 2, 3651-3658 (2014).
168. Wang, X. et al. A Zn-NiO rechargeable battery with long lifespan and high energy density. J. Mater. Chem. A 3, 8280-8283 (2015).

169. Wang, X. et al. $\mathrm{CO}_{3} \mathrm{O}_{4} @$ MWCNT nanocable as cathode with superior electrochemical performance for supercapacitors. ACS Appl. Mater. Interfaces 7 2280-2285 (2015).

170. Wang, $X$. et al. Orientated $\mathrm{CO}_{3} \mathrm{O}_{4}$ nanocrystals on MWCNTs as superior battery-type positive electrode material for a hybrid capacitor. J. Electrochem. Soc. 162, A1966-A1971 (2015).

171. Koussi-Daoud, S., Majerus, O., Schaming, D. \& Pauporté, T. Electrodeposition of $\mathrm{NiO}$ films and inverse opal organized layers from polar aprotic solventbased electrolyte. Electrochim. Acta 219, 638-646 (2016).

172. Li, J., Liu, Z., Li, L., Zhu, C. \& Hu, D. Interpenetrating framework with threedimensionally ordered macroporous carbon substrates and well-dispersed $\mathrm{CO}_{3} \mathrm{O}_{4}$ nanocrystals for supercapacitor. J. Electrochem. Soc. 163, A417-A426 (2016).

173. Wang, Y., Song, Y. \& Xia, Y. Electrochemical capacitors: mechanism, materials, systems, characterization and applications. Chem. Soc. Rev. 45, 5925-5950 (2016).

174. Deng, M. J. et al. Three-dimensionally ordered macroporous $\mathrm{Cu}_{2} \mathrm{O} / \mathrm{Ni}$ inverse opal electrodes for electrochemical supercapacitors. Phys. Chem. Chem. Phys. 15, 7479-7483 (2013).

175. Zhang, W. et al. $\ln _{2} \mathrm{O}_{3}$ nanoparticles on three-dimensionally ordered macroporous (3DOM) carbon for pseudocapacitor electrodes. Electrochim. Acta 176, 861-867 (2015).

176. Mahmood, Q. et al. Unveiling surface redox charge storage of interacting two-dimensional heteronanosheets in hierarchical architectures. Nano Lett. 15, 2269-2277 (2015).

177. Kim, S. K., Cho, J., Moore, J. S., Park, H. S. \& Braun, P. V. High-performance mesostructured organic hybrid pseudocapacitor electrodes. Adv. Funct. Mater. 26, 903-910 (2016).

178. Zhang, D. et al. Preparation of a three-dimensional ordered macroporous carbon nanotube/polypyrrole composite for supercapacitors and diffusion modeling. J. Phys. Chem. C 117, 20446-20455 (2013).

179. Woo, S. W., Dokko, K. \& Kanamura, K. Composite electrode composed of bimodal porous carbon and polypyrrole for electrochemical capacitors. J. Power Sources 185, 1589-1593 (2008).

180. Woo, S. W., Dokko, K., Nakano, H. \& Kanamura, K. Incorporation of polyaniline into macropores of three-dimensionally ordered macroporous carbon electrode for electrochemical capacitors. J. Power Sources 190, 596-600 (2009).

181. Zhao, Y. et al. Superior stable and long life sodium metal anodes achieved by atomic layer deposition. Adv. Mater. https://doi.org/10.1002/adma.201606663 (2017)

182. Luo, W. et al. Encapsulation of metallic $\mathrm{Na}$ in an electrically conductive host with porous channels as a highly stable Na metal anode. Nano Lett. 17 3792-3797 (2017).

183. Lukatskaya, M. R. et al. Ultra-high-rate pseudocapacitive energy storage in two-dimensional transition metal carbides. Nat. Energy 2, 17105 (2017).

184. Mannix, A. J., Kiraly, B., Hersam, M. C. \& Guisinger, N. P. Synthesis and chemistry of elemental 2D materials. Nat. Rev. Chem. https://doi.org/10.1038/ s41570-016-0014 (2017)

185. Shen, K. et al. Ordered macro-microporous metal-organic framework single crystals. Science 359, 206-210 (2018)

186. Wang, F. et al. A dual-stimuli-responsive sodium-bromine battery with ultrahigh energy density. Adv. Mater. 30, 1800028 (2018).

187. Yu, F. et al. Pseudocapacitance contribution in boron-doped graphite sheets for anion storage enables high-performance sodium-ion capacitors. Mater. Horiz. 5, 529-535 (2018).

188. Zhang, P. et al. Exposed high-energy facets in ultradispersed sub-10 nm SnO nanocrystals anchored on graphene for pseudocapacitive sodium storage and high-performance quasi-solid-state sodium-ion capacitors. NPG Asia Mater. 10, 429-440 (2018).

189. Grey, C. P. \& Tarascon, J. M. Sustainability and in-situ monitoring in battery development. Nat. Mater. 16, 45-56 (2017).

190. Zhu, C., Usiskin, R. E., Yu, Y. \& Maier, J. The nanoscale circuitry of battery electrodes. Science 358, eaao2808 (2017).

191. Tavassol, H., Jones, E. M., Sottos, N. R. \& Gewirth, A. A. Electrochemical stiffness in lithium-ion batteries. Nat. Mater. 15, 1182-1187 (2016).

192. Zhang, $\mathrm{H}$. et al. Electroplating lithium transition metal oxides. Sci. Adv. 3 e1602427 (2017) 